\title{
Influence of two major phase transitions on mantle convection with moving and subducting plates
}

\author{
Masaki Yoshida \\ Earth Simulator Center, Japan Agency for Marine-Earth Science and Technology, \\ 3173-25 Showa-machi, Kanazawa-ku, Yokohama, Kanagawa 236-0001, Japan \\ (Received March 9, 2004; Revised September 2, 2004; Accepted September 7, 2004)
}

\begin{abstract}
A series of numerical simulation has been carried out to explore the influence of two major phase transitions at $410 \mathrm{~km}$ and $660 \mathrm{~km}$ phase boundaries on mantle convection with self-consistently moving and subducting plates, that is, on the "plate-like regime" of mantle convection. The degree of Clausius-Clapeyron slope at the $660 \mathrm{~km}$ phase boundary is systematically changed within the range estimated by high pressure experiments. On the plate-like regime where moving plates continuously subduct, as the Clausius-Clapeyron slope is steepened, the upwelling plumes originating from the bottom thermal boundary layer are less buoyant owing to the increase of average mantle temperature, so that the upwelling plumes are hard to penetrate through the $660 \mathrm{~km}$ phase boundary. Investigations reveal that three types of small upwelling plumes in the upper mantle are found on the plate-like regime: (1) The secondary plumes directly derived from the upwelling plumes from the lower mantle, (2) the passive upwellings from the shallow parts of the lower mantle due to the diffused return flow by continuously subducting plates, and (3) the secondary plumes originating from the $660 \mathrm{~km}$ phase boundary caused by the development of the small-scale convection cells confined in the upper mantle.
\end{abstract}

Key words: Numerical simulation, mantle convection, phase transition, moving plate, subducting plate, platelike regime.

\section{Introduction}

Many studies, using full dynamic models of mantle convection, have demonstrated that the mineralogical solidsolid endothermic phase transition at $660 \mathrm{~km}$ depth and/or exothermic phase transition at $410 \mathrm{~km}$ depth have a significant influence on the behavior of convection in the Earth's mantle. Their studies have been done in convection models with the uniform or pressure- (depth-) dependent viscosity (e.g., Christensen and Yuen, 1985; Machetel and Weber, 1991; Peltier and Solheim, 1992; Zhao et al., 1992; Tackley et al., 1993; Steinbach et al., 1993; Weinstein, 1993; Honda et al., 1993; Tackley et al., 1994; Steinbach and Yuen, 1994; Nakakuki and Fujimoto, 1994; Yuen et al., 1994; Solheim and Peltier, 1994a, 1994b; Ita and King, 1994; Monnereau and Rabinowicz, 1996; Tackley, 1996b; Bunge et al., 1997; Steinbach and Yuen, 1997; Cserepes and Yuen, 1997; Cserepes and Yuen, 2000; Cserepes et al., 2000), and the temperature-dependent viscosity, (e.g., Zhong and Gurnis, 1994; Nakakuki et al., 1994; King and Ita, 1995; Steinbach and Yuen, 1995, 1997; Brunet and Machetel, 1998; Brunet and Yuen, 2000). Because of the nature of uniform or weakly temperature-dependent viscosity, they have shown that the cold downwelling plumes frequently arise from surface boundary layer of the convecting vessel and easily deflect at the endothermic $660 \mathrm{~km}$ phase

Copy right(c) The Society of Geomagnetism and Earth, Planetary and Space Sciences (SGEPSS); The Seismological Society of Japan; The Volcanological Society of Japan; The Geodetic Society of Japan; The Japanese Society for Planetary Sciences; TERRAPUB boundary. In the actual Earth's mantle, however, highly viscous moving and subducting plates are a dominant part of mantle convection and induce a large-scale convective flow (e.g., Davies, 1999). Therefore it is crucial to address the issue of the effects of the phase transition(s) on mantle convection pattern with moving and subducting plates.

It has been controversial where the upwelling plumes originate. Most of upwelling plumes may come from the deep mantle, probably around the core-mantle boundary (CMB) (e.g., Morgan, 1971, 1972; Loper and Stacey, 1983; Davies, 1988; White and McKenzie, 1989; Larson, 1991; Duncan and Richards, 1991), or from around the 660 km phase boundary (e.g., McKenzie and O'Nions, 1983; Allègre and Turcotte, 1985; Hofmann, 1997), or from other thermal boundaries in the mantle. Recent seismic tomography studies have indicated that hot and narrow plumes originate from the lower mantle (Shen et al., 1998) and suggest the existence of the plume tail in the D" layer, especially, beneath Iceland (Bijwaard et al., 1998; Bijwaard and Sparkman, 1999). Indeed, hotspots are generally located above the low seismic velocity regions in the lower mantle (e.g., Su et al., 1994; Zhao, 2001) and ultra-low-velocity zones on the CMB (Williams et al., 1998; Garnero et al., 1998). Small-scale upwelling plumes in the upper mantle, some of which are observed as hotspot on the Earth's surface, are imaged by recent seismic tomography models. Rhodes and Davies (2001), using a high-resolution global tomography inversion, showed an image of cylindrical slow velocities in the upper and lower mantle beneath many current hotspot 
Table 1. Parameters used in this study. The dimensional parameters are refered with hats in the text.

\begin{tabular}{|c|c|c|}
\hline Symbols & Meanings & Dimensional values \\
\hline$c_{p 0}$ & reference specific heat at constant pressure & $1.2 \times 10^{3} \mathrm{~J} \mathrm{~kg}^{-1} \mathrm{~K}^{-1}$ \\
\hline$D$ & thickness of the mantle & $2.9 \times 10^{6} \mathrm{~m}$ \\
\hline$g$ & reference gravity acceleration & $9.8 \mathrm{~m} \mathrm{~s}^{-2}$ \\
\hline$H_{R}$ & volumetric internal heating rate per unit mass & $1.0 \times 10^{-12} \mathrm{~W} \mathrm{~kg}^{-1}$ \\
\hline$k_{0}$ & reference thermal conductivity & $4.0 \mathrm{~W} \mathrm{~m}^{-1} \mathrm{~K}^{-1}$ \\
\hline$T_{t o p}$ & temperature at the top surface & $273 \mathrm{~K}$ \\
\hline$T_{\text {bot }}$ & temperature at the bottom surface & $1873 \mathrm{~K}$ \\
\hline$T_{\text {ref }}$ & reference temperature of upper mantle & $1573 \mathrm{~K}$ \\
\hline$\Delta T$ & temperature contrast across the mantle & $1600 \mathrm{~K}$ \\
\hline$\alpha_{0}$ & reference thermal expansivity & $2.0 \times 10^{-5} \mathrm{~K}^{-1}$ \\
\hline$\eta_{0}$ & reference viscosity of asthenosphere & $1.0 \times 10^{20} \mathrm{~Pa} \mathrm{~s}$ \\
\hline$\kappa_{0}$ & reference thermal diffusivity & $1.0 \times 10^{-6} \mathrm{~m}^{2} \mathrm{~s}^{-1}$ \\
\hline$\rho_{0}$ & reference density & $3.3 \times 10^{3} \mathrm{~kg} \mathrm{~m}^{-3}$ \\
\hline$d_{410}$ & depth of $410 \mathrm{~km}$ phase transition & $4.1 \times 10^{5} \mathrm{~m}$ \\
\hline$d_{660}$ & depth of $660 \mathrm{~km}$ phase transition & $6.6 \times 10^{5} \mathrm{~m}$ \\
\hline$w_{p h}$ & width of phase transitions & $4.0 \times 10^{4} \mathrm{~m}$ \\
\hline$\rho_{p h}$ & mean density at phase transitions & \\
\hline$\rho_{410}$ & $\rho_{p h}$ at $410 \mathrm{~km}$ depth & $3.6 \times 10^{3} \mathrm{~kg} \mathrm{~m}^{-3}$ \\
\hline$\rho_{660}$ & $\rho_{p h}$ at $660 \mathrm{~km}$ depth & $4.2 \times 10^{3} \mathrm{~kg} \mathrm{~m}^{-3}$ \\
\hline$\Delta \rho_{p h}$ & density contrast of phase transitions & \\
\hline$\Delta \rho_{410}$ & $\Delta \rho_{p h}$ of $410 \mathrm{~km}$ phase transition & $2.5 \times 10^{2} \mathrm{~kg} \mathrm{~m}^{-3}$ \\
\hline$\Delta \rho_{660}$ & $\Delta \rho_{p h}$ of $660 \mathrm{~km}$ phase transition & $4.0 \times 10^{2} \mathrm{~kg} \mathrm{~m}^{-3}$ \\
\hline$\chi_{p h}$ & Clausius-Clapeyron slope & \\
\hline$\chi_{410}$ & $\chi_{p h}$ of $410 \mathrm{~km}$ phase transition & $0.0 \sim+2.0 \mathrm{~Pa} \mathrm{~K}^{-1}($ see Table 2$)$ \\
\hline$\chi_{660}$ & $\chi_{p h}$ of $660 \mathrm{~km}$ phase transition & $-1.5 \sim-4.0 \mathrm{~Pa} \mathrm{~K}^{-1}($ see Table 2$)$ \\
\hline
\end{tabular}

locations. On the other hand, there are some studies that argue that the plume beneath Iceland is restricted to the upper mantle (Foulger et al., 2000, 2001; Foulger and Pearson, 2001). These conflicting results indicate that mantle plumes are very difficult to see clearly from current seismic imaging, because its resolution is not adequate to detect narrow cylindrical tails of plumes whose horizontal scale may be only a few hundreds of kilometers (e.g., Nataf, 2000). Therefore it is essential to examine the origin of mantle plumes by numerical modeling efforts.

In this paper, we investigate the influence of the two major phase transitions on a two-dimensional (2-D) mantle convection with plate-like behavior. From the results obtained here, we focus on the interaction between the upwelling plumes and the phase transition(s), and explore the origin of small-scale upwelling plumes in the upper mantle.

\section{Numerical Methods}

\subsection{Model}

A thermal convection of an incompressible fluid is considered in a 2-D Cartesian ( $x$ in horizontal coordinate and $z$ in vertical coordinate) box with $D=2900 \mathrm{~km}$ in thickness and an aspect ratios of 5. The Prandtl number is infinite and the Boussinesq approximation is employed. All of the boundaries of the convecting box are impermeable and shear stress-free, that is, the reflective condition is applied to the sidewalls. The top and bottom surface boundary ( $z_{0} \equiv z=0$ and $z_{1} \equiv z=1$, respectively) are isothermal; $T_{\text {top }}$ (temperature at the top surface) $=1$ at $z_{0}$, and $T_{b o t}$ (temperature at the bottom surface) $=0$ at $z_{1}$, respectively. The normalization factors for the non-dimensionalization of the length, velocity, time and temperature are $\hat{D}, \hat{\kappa}_{0} / \hat{D}$, $\hat{D}^{2} / \hat{\kappa}_{0}$ and $\hat{\Delta T}=\hat{T}_{\text {bot }}-\hat{T}_{\text {top }}$, respectively, where $\hat{\kappa}_{0}$ is the reference thermal diffusivity (Note that the quantities with hats stand for dimensional. All the dimensional quantities used in this study are listed in Table 1).

\subsection{Basic equations}

Under the standard Boussinesq approximation, the nondimensionalized continuity, momentum and energy equations are,

$$
\begin{gathered}
\nabla \cdot \boldsymbol{v}=0, \\
-\nabla \cdot \boldsymbol{\sigma}+\boldsymbol{f}=0,
\end{gathered}
$$

and,

$$
\frac{\partial T}{\partial t}+\boldsymbol{v} \cdot \nabla T=\nabla \cdot(\nabla T)+H_{R},
$$

respectively, where $\boldsymbol{v}=\left(v_{x}, v_{z}\right)$ is the velocity vector, $\boldsymbol{f}$ the buoyancy force, and $t$ is the time. The total stress tensor $\sigma$ 
is written as,

$$
\boldsymbol{\sigma}=-p \boldsymbol{I}+\boldsymbol{\tau},
$$

where $p$ is the pressure, and $\boldsymbol{I}$ is the unit tensor. The deviatoric stress tensor $\tau$ is given by,

$$
\tau=\eta\left[\nabla v+{ }^{t}(\nabla v)\right],
$$

where $\eta$ is the viscosity (see Section 2.3), and the brackets ${ }^{t}(\quad)$ indicates a tensor transpose.

Now considering only the thermal origin of the buoyancy, $f$ is given by,

$$
\boldsymbol{f}=\operatorname{RaT} \boldsymbol{e}_{z},
$$

where $\boldsymbol{e}_{z}$ is the unit vector in the vertical direction with positive upward. The Rayleigh number $R a$ based on the reference viscosity $\hat{\eta}_{0}$ is defined by,

$$
R a \equiv \frac{\hat{\rho_{0}} \hat{g} \hat{\alpha}_{0} \Delta T \hat{D}^{3}}{\hat{\kappa}_{0} \hat{\eta}_{0}},
$$

where $\hat{\rho}_{0}$ is the reference density, $\hat{g}$ the gravitational acceleration, and $\hat{\alpha}_{0}$ is the thermal expansivity. We fixed $R a$ at $2.52 \times 10^{8}$. This $R a$ corresponds to $\hat{\eta}_{0}=1.0 \times 10^{20} \mathrm{~Pa} \cdot \mathrm{s}$. The non-dimensional internal heating rate per unit volume is defined by,

$$
H_{R} \equiv \frac{\hat{\rho}_{0} \hat{H}_{R} \hat{D}^{2}}{\hat{k}_{0} \Delta T}
$$

where $\hat{H}_{R}$ is the uniform volumetric internal heating rate per unit mass fixed at $1.0 \times 10^{-12} \mathrm{~W} \mathrm{~kg}^{-1}$, and $\hat{k}_{0}$ is the thermal conductivity, and hence, we fixed $H_{R}$ at 4.34. At this $H_{R}$, the contribution of internal source to the overall heating of the mantle is about a third of that of the basal heating in the convecting pattern with plate-like behavior (Yoshida, 2003).

\subsection{Damage parameter and viscosity}

The temperature-dependent viscosity is necessary to model the stiff "lid" (i.e., the lithosphere), that is, the cold, thick thermal boundary layer along the top surface boundary. Here, to make the lithosphere show a plate-like behavior in the convection, we introduced a "damage parameter" $\omega$ that represents the "degree of damage" into the viscosity equation (Bercovici, 1998; Tackley, 2000; Ogawa, 2003).

The damage parameter $\omega$ evolves with time $t$, and is expressed as,

$$
\frac{\partial \omega}{\partial t}+\boldsymbol{v} \cdot \nabla \omega=\Gamma \tau_{i j} \dot{\epsilon}_{i j}-\lambda \exp (E T) \cdot \omega,
$$

where $\Gamma$ and $\lambda$ are constant. This equation implies that (i) the damaging rate is assumed to be proportional to viscous dissipation rate as is the case for void-volatile weakening (e.g., Bercovici, 1998) and (ii) the convecting material recovers from damage with a healing time that depends on temperature. The healing time $1 / \lambda\left(\equiv \lambda_{0}\right)$ at $T=0$ is $10^{-5}$. There is no flow of $\omega$ across any of the boundaries.

We assumed that the viscosity of convecting materials exponentially depended on the $\omega$, as well as the temperature $T$ and the depth $d=(1-z)$ as,

$$
\eta(T, d, \omega)=\exp \left[-E\left(T-T_{r e f}\right)+V d-F \frac{\omega}{1+\omega}\right],
$$

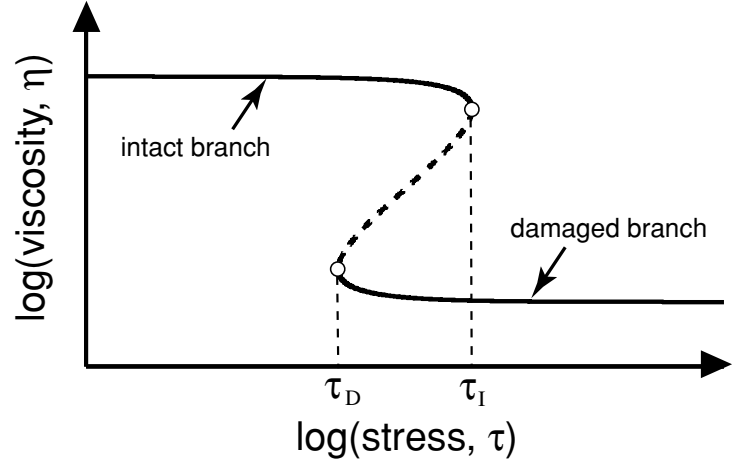

Fig. 1. The relationship of viscosity $\eta$ versus stress $\tau$. The convecting fluid selects one of the two branches indicated by the solid parts of the curve, i.e., "intact branch" or "damaged branch" in the stress range from $\tau_{D}$ to $\tau_{I}$, depending on the stress-history that the fluid has experienced in the past. The dashed part of the curve is physically unrealizable.

(Ogawa, 2003; Yoshida and Ogawa, 2004), where constants $E, V$ and $F$ are the degree of temperature-, depth-, and $\omega$ dependence of viscosity, respectively. The value of $V$ is fixed at $\ln 10^{2}=4.61$. This implies that the assumed viscosity contrast between top and bottom boundaries of convecting box due to the pressure effect is comparable to the viscosity contrast between asthenosphere and deep mantle, which is around two orders of magnitude as obtained from post-glacial rebound studies (e.g., Peltier, 1998). We treated $E$ as a free parameter that make convective regime change. The reference temperature $T_{\text {ref }}$ is taken to be 0.8125 (i.e., $\left.\hat{T}_{\text {ref }}=1573^{\circ} \mathrm{C}\right)$, a characteristic temperature in the upper mantle (e.g., Mckenzie and Bickle, 1988). We fixed $F$ at $\ln 10^{5}=11.51$.

Because of the short healing time, the steady state assumption holds well for Eq. (9), the left hand side of Eq. (9) is usually negligible (see, Ogawa (2003) for details). Therefore, substituting Eq. (10) into Eq. (9),

$$
\frac{\tau^{2} \Gamma}{\lambda_{0} \eta^{\dagger}(d)}=\omega \exp \left(-F \frac{\omega}{1+\omega}\right)
$$

where $\eta^{\dagger}(d) \equiv \exp \left(E T_{\text {ref }}+V d\right)$, and $\tau\left(=\tau_{\text {II }}\right)$ is the second invariant of deviatoric stress tensor, $\tau_{\mathrm{II}} \equiv$ $\sqrt{\frac{1}{2} \sum_{i, j} \tau_{i j} \tau_{i j}}(i, j=x, z)$. Under this assumption, Equation (11) gives a hysteresis with the relationship between stress $\tau$ and viscosity $\eta$, so that the viscosity depends on stress-history. The critical stress $\tau_{I}$ in Fig. 1 is the maximum stress on the "intact branch", which is characterized by $\omega \ll 1$ in Eq. (9) and corresponds to the rupture strength of "plate interior", whereas $\tau_{D}$ is the minimum stress on the "damaged branch", which is characterized by $\omega \gg 1$ and corresponds to the rupture strength of "plate margins". The convecting fluid selects one of the two branches in the stress range from $\tau_{D}$ to $\tau_{I}$ depending on the stress-history that the fluid has experienced. In 2-D geometry, plate-like behavior of the lithosphere emerges when the stress induced by the weight of the lithosphere itself is within the range between $\tau_{D}$ and $\tau_{I}$. This criterion physically implies that a platelike behavior arises only when the mechanical strength of plates (plate margins) is high (low) enough to endure (yield to) the stress induced by the weight of plates themselves. 
To make the dimensional $\tau_{I}$ and $\tau_{D}$ close to the values that is appropriate for the Earth's mantle, we assumed that $\Gamma=2.0 \times 10^{-5}$. When $F=\ln \left(10^{5}\right)$, the adopted value of $\Gamma$ implies that the dimensional $\tau_{I}$ and $\tau_{D}$ are in the range of $O(10) \sim O(100) \mathrm{MPa}$ and $O(1) \sim O(10) \mathrm{MPa}$ (Yoshida, 2003, 2004).

\subsection{Phase transition(s)}

We take account of two major phase transitions of mantle materials, the endothermic $\gamma$-spinel to perovskite + magnesiowüstite transformation at $660 \mathrm{~km}$ depth $\left(d_{660}=0.228\right)$ and the exthothermic olivine to $\beta$-spinel transformation at $410 \mathrm{~km}$ depth $\left(d_{410}=0.141\right)$. Hereafter, we call these phase transitions the "410 km phase transition" at the "410 km phase boundary" and the "660 km phase transition" at the "660 km phase boundary", respectively. The $660 \mathrm{~km}$ phase boundary is a boundary between the upper mantle and the lower mantle.

To express the phase transitions, we adopted the nondimensional "phase transition function" $\gamma_{p h}$ which expressed the degree of phase transition and varied between 0 and 1 as a function of temperature and depth (e.g., Richter, 1973; Christensen and Yuen, 1985);

$$
\gamma_{p h}=\frac{1}{2}\left(1+\tanh \frac{d-d_{p h 0}-\chi_{p h} T}{w_{p h}}\right),
$$

where $w_{p h}$ is the half-width of the phase transitions, $d_{p h 0}$ is the depth of the phase boundaries at $\hat{T}=0 \mathrm{~K}$, and $\chi_{p h}$ is the Clausius-Clapeyron slope. In estimation by high pressure experiments, the Clausius-Clapeyron slope of the 410 $\mathrm{km}$ phase boundary $\left(\hat{\chi}_{410}\right)$ is in a range from $+1.5 \mathrm{MPaK}^{-1}$ to $+2.9 \mathrm{MPaK}^{-1}$ (e.g., Akaogi et al., 1989; Katsura and Ito, 1989; Bina and Helffrich, 1994), and the ClausiusClapeyron slope of the $660 \mathrm{~km}$ phase boundary $\left(\hat{\chi}_{660}\right)$ is in a range from $-1.5 \mathrm{MPaK}^{-1}$ to $-4.0 \mathrm{MPaK}^{-1}$ (e.g., Ito and Takahashi, 1989; Ito et al., 1990; Akaogi and Ito, 1993; Bina and Helffrich, 1994; Chopelas et al., 1994). Because there are uncertainties in the estimates of the ClausiusClapeyron slopes, we treated them as a free parameter in this study (see Table 2 and Section 3).

The "phase boundary Rayleigh number" $R a_{p h}$ (Christensen and Yuen, 1985) is defined by,

$$
R a_{p h} \equiv \frac{\hat{\Delta} \rho_{p h} \hat{g} \hat{D}^{3}}{\hat{\eta}_{0} \hat{\kappa}_{0}},
$$

where the density increases at $410 \mathrm{~km}$ and $660 \mathrm{~km}$ phase boundaries are $\Delta \rho_{410}=7 \%$ and $\Delta \rho_{660}=10 \%$, respectively (e.g., Christensen, 1995). Thus we assumed that $R a_{p h}$ at $410 \mathrm{~km}$ and $660 \mathrm{~km}$ boundaries were $R a_{410}=5.98 \times 10^{8}$ and $R a_{660}=9.56 \times 10^{8}$, respectively.

Considering the effects of phase transition(s), the buoyancy force term $\boldsymbol{f}$ in Eq. (2) is re-written as,

$$
\boldsymbol{f}=\left(R a T-\sum^{n_{p h}} R a_{p h} \gamma_{p h}\right) \boldsymbol{e}_{z},
$$

where $n_{p h}$ is the number of phase transition (in this paper, $n_{p h}=1$ is for the cases with only the $660 \mathrm{~km}$ phase boundary and $n_{p h}=2$ for the cases both with the $660 \mathrm{~km}$ and with $410 \mathrm{~km}$ phase boundaries).
We considered the effects of latent heat release or absorption from the phase transition(s) in the Boussinesq approximation (see, Ogawa and Nakamura (1998) for details) instead of the earlier suggestion by Christensen and Yuen (1985), who claimed that the latent heat should be dropped in the framework of Boussinesq approximation. The rate of latent heat release or absorption per unit volume during the phase transitions $H_{L}$ is calculated from phase transition function $\gamma_{p h}$. This is converted into a non-dimensional form by Christensen and Yuen (1985);

$$
H_{L}=\chi_{p h} \frac{R a_{p h}}{R a} D i\left(T+T_{\text {top }}\right) \frac{D \gamma_{p h}}{D t},
$$

where the $D / D t$ denotes the material derivative, and the dissipation number $D i$ is given by,

$$
D i \equiv \frac{\hat{\alpha}_{0} \hat{g} \hat{D}}{\hat{c_{p_{0}}}},
$$

where $\hat{c_{p_{0}}}$ is the specific heat at constant pressure. We assumed $D i=0.45$ which was appropriate for the Earth's mantle. The energy equation of Eq. (3) in a nondimensional form is, therefore, re-written by,

$$
\frac{\partial T}{\partial t}+\boldsymbol{v} \cdot \nabla T=\nabla \cdot(\nabla T)+H_{R}+\sum^{n_{p h}} H_{L} .
$$

\subsection{Numerical techniques and resolutions}

The basic equations are descritized by finite volume method on a staggered grid using STAG3D (e.g., Tackley, 1996a). A repeated iterative solver with SOR-like method procedure is used to solve the velocity and pressure fields separately (Patankar, 1980). The explicit time-stepping method, MPDATA (Multidimensional Positive Definite Advection Transport Algorithm) scheme with a second-order time accuracy (Smolarkiewicz, 1983, 1984; Smolarkiewicz and Clark, 1986) is used for the calculation of advection terms in the energy equation (Eq. (3)) and the equation for time evolution of the damage parameter (Eq. (9)). The diffusive term in energy equation is calculated by the secondorder finite difference method. The healing term in Eq. (9) is implicitly treated. The time-steps are determined from the Courant condition with the Courant number of $0.1 \sim$ 0.5 .

As the initial condition for the energy equation and the equation for time evolution of the damage parameter, we adopt either the temperature- and $\omega$-fields of

$$
T(x, z)=0.5+0.01 \cos (2 \pi x) \sin (\pi z),
$$

and

$$
\omega(x, z)=0,
$$

respectively, or those obtained from the previous calculation.

The adopted mesh is uniform in the horizontal direction but non-uniform in the vertical direction with higher resolution around the top surface, bottom surface and phase boundaries. The number of mesh points are 512 in the horizontal direction, and 100 in the vertical direction when only the $660 \mathrm{~km}$ phase boundary is included, and 110 in the vertical direction when both the $660 \mathrm{~km}$ and the $410 \mathrm{~km}$ phase 
Table 2. Summary of computations carried out in this study.

\begin{tabular}{|c|c|c|c|c|c|}
\hline Case names & $E$ & $\chi_{660}\left[\mathrm{~Pa} \mathrm{~K}^{-1}\right]$ & $\chi_{410}\left[\mathrm{~Pa} \mathrm{~K}{ }^{-1}\right]$ & Regimes & Figures \\
\hline \multicolumn{6}{|c|}{ Series PL-1 } \\
\hline P1500P & 17.27 & $-1.5 \mathrm{M}$ & $0.0 \mathrm{M}$ & plate-like & Fig. 3(a) \\
\hline $\mathrm{P} 2500 \mathrm{P}$ & 17.27 & $-2.5 \mathrm{M}$ & $0.0 \mathrm{M}$ & plate-like & Fig. 2 \\
\hline P4000P & 17.27 & $-4.0 \mathrm{M}$ & $0.0 \mathrm{M}$ & plate-like & Fig. 3(b) \\
\hline \multicolumn{6}{|c|}{ Series WP-1 } \\
\hline P1500W & 14.97 & $-1.5 \mathrm{M}$ & $0.0 \mathrm{M}$ & weak-plate & Fig. 5(a) \\
\hline $\mathrm{P} 2500 \mathrm{~W}$ & 14.97 & $-2.5 \mathrm{M}$ & $0.0 \mathrm{M}$ & weak-plate & Fig. 5(b) \\
\hline P4000W & 14.97 & $-4.0 \mathrm{M}$ & $0.0 \mathrm{M}$ & weak-plate & Fig. 5(c) \\
\hline \multicolumn{6}{|c|}{ Series ST-1 } \\
\hline P1500S & 19.57 & $-1.5 \mathrm{M}$ & $0.0 \mathrm{M}$ & stagnant-lid & Fig. 7(a) \\
\hline P2500S & 19.57 & $-2.5 \mathrm{M}$ & $0.0 \mathrm{M}$ & stagnant-lid & Fig. 7(b) \\
\hline P4000S & 19.57 & $-4.0 \mathrm{M}$ & $0.0 \mathrm{M}$ & stagnant-lid & Fig. 7(c) \\
\hline \multicolumn{6}{|c|}{ Series PL-2 } \\
\hline P1520P & 17.27 & $-1.5 \mathrm{M}$ & $+2.0 \mathrm{M}$ & plate-like & Fig. 10(a) \\
\hline $\mathrm{P} 2520 \mathrm{P}$ & 17.27 & $-2.5 \mathrm{M}$ & $+2.0 \mathrm{M}$ & plate-like & Fig. 9 \\
\hline $\mathrm{P} 4020 \mathrm{P}$ & 17.27 & $-4.0 \mathrm{M}$ & $+2.0 \mathrm{M}$ & plate-like & Fig. 10(b) \\
\hline \multicolumn{6}{|c|}{ Series WP-2 } \\
\hline P1520W & 14.97 & $-1.5 \mathrm{M}$ & $+2.0 \mathrm{M}$ & weak-plate & Fig. 12(a) \\
\hline P2520W & 14.97 & $-2.5 \mathrm{M}$ & $+2.0 \mathrm{M}$ & weak-plate & Fig. 12(b) \\
\hline P4020W & 14.97 & $-4.0 \mathrm{M}$ & $+2.0 \mathrm{M}$ & weak-plate & Fig. 12(c) \\
\hline \multicolumn{6}{|c|}{ Series ST-2 } \\
\hline P1520S & 19.57 & $-1.5 \mathrm{M}$ & $+2.0 \mathrm{M}$ & stagnant-lid & Fig. 14(a) \\
\hline P2520S & 19.57 & $-2.5 \mathrm{M}$ & $+2.0 \mathrm{M}$ & stagnant-lid & Fig. 14(b) \\
\hline P4020S & 19.57 & $-4.0 \mathrm{M}$ & $+2.0 \mathrm{M}$ & stagnant-lid & Fig. 14(c) \\
\hline
\end{tabular}

boundaries are included, respectively. The minimal mesh size is $3.0 \times 10^{-3}$ or around $10 \mathrm{~km}$ in the vertical direction. The differences in vertical grid intervals between two adjacent grids are less than $5 \%$ throughout the depth of the convective layer.

\subsection{Vertical mass flux diagnosis}

In this study, to quantify the degree of layering due to the phase transitions, a diagnosis of vertical mass flux proposed by Peltier and Solheim (1992) is used. The vertical mass flux diagnosis is the absolute vertically-averaged mass flux $\left\langle\rho_{0}\left|v_{z}\right|\right\rangle$ at a depth normalized so that the integral over depth is unity,

$$
\Omega_{p h} \equiv \frac{\left\langle\rho_{0}\left|v_{z}\right|\right\rangle}{\frac{1}{z_{1}-z_{0}} \int_{z_{0}}^{z_{1}}\left\langle\rho_{0}\left|v_{z}\right|\right\rangle d z}
$$

Note that the values of $\Omega_{p h}$ at the top and bottom surface boundaries are always zero because of the impermeable boundary conditions.

\section{Results}

In Table 2, we summarized all the calculations carried out in this paper. For all the cases searched in this study, we continued calculations until time-series of averaged quantities such as Nusselt number and root-mean-square velocity reached statistically steady states. At least 300,000 500,000 time-steps were necessary to obtain the statistically steady state result.

\subsection{The cases with $660 \mathrm{~km}$ phase boundary}

Because the $660 \mathrm{~km}$ endothermic phase transition has major effects on the convective flow pattern, we first employed a series of numerical calculations when only the 660 $\mathrm{km}$ phase boundary is included (Series PL-1, WP-1 and SP1 in Table 2). In each series, the Clausius-Clapeyron slope $\hat{\chi}_{660}$ is chosen three values, $-1.5 \mathrm{MPa} / \mathrm{K},-2.5 \mathrm{MPa} / \mathrm{K}$ and $-4.0 \mathrm{MPa} / \mathrm{K}$, which is within the range estimated by high pressure experiments as referred in Section 2.4.

3.1.1 Plate-like regime (Series PL-1) Taking the degree of temperature-dependence of viscosity $E$ to be $\ln 10^{7.5}=17.27$, we carried out calculations on the "plate- 


\section{Case P2500P}
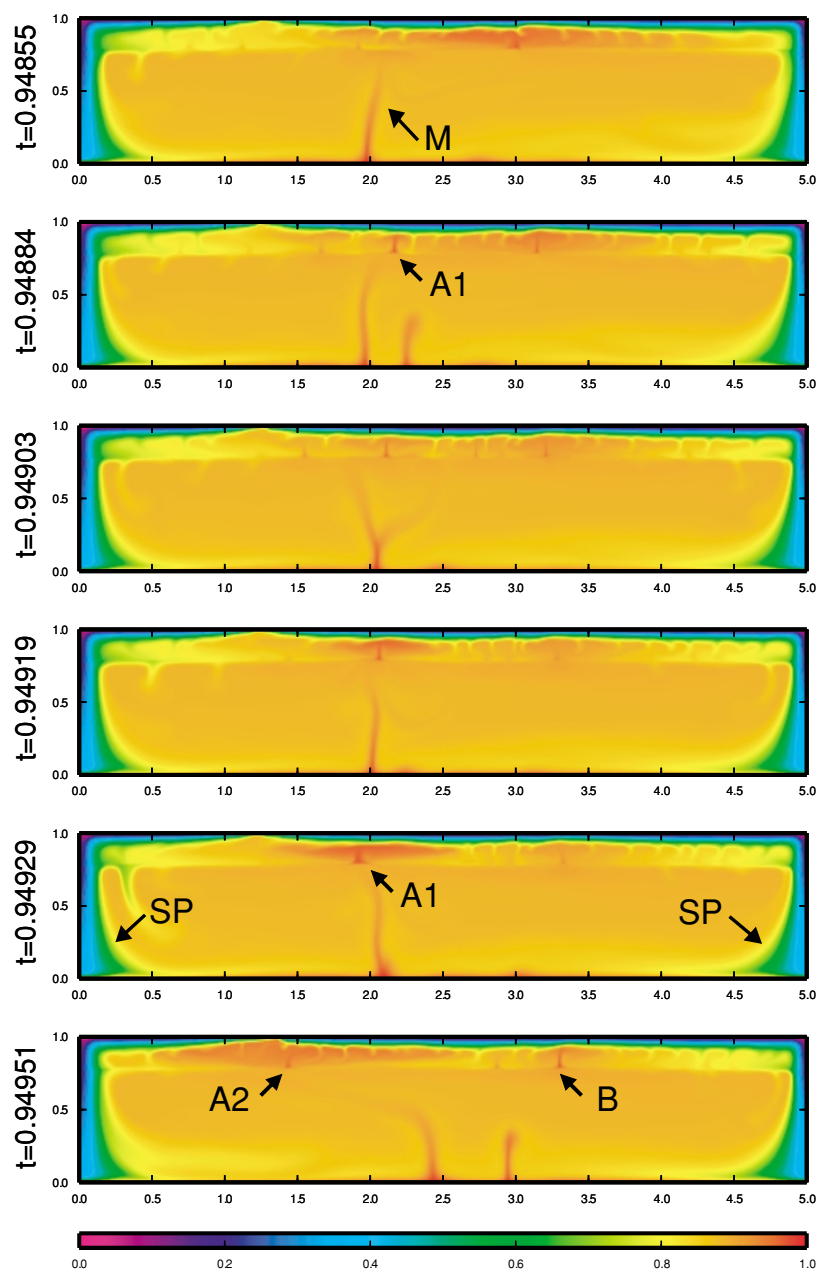

Fig. 2. The time-series of temperature fields for Case P2500P. The non-dimensional elapsed time $t=0.001$ corresponds to $267 \mathrm{Myr}$ in dimensional time.

like regime" (Ogawa, 2003) in Series PL-1. On the platelike regime, the stress-history dependence due to hysteresis shown in Fig. 1 induces the plate-like regime where "plates" or highly viscous pieces of "lithosphere", separated by narrow and mechanically "weak plate margins", rigidly move by their weight and subduct into the mantle.

Shown in Fig. 2 is a time-series of typical convective flow pattern for Case P2500P where $\hat{\chi}_{660}$ is $-2.5 \mathrm{MPa} / \mathrm{K}$. This slope is within the range that is appropriate for the $660 \mathrm{~km}$ phase boundary of the mantle. The hot upwelling plume from the bottom thermal boundary layer (hereafter, "mother plumes"; arrow "M" in Fig. 2) penetrates through the $660 \mathrm{~km}$ phase boundary and induces secondary upwelling plume (hereafter, "daughter plume") that uprise in the upper mantle from the $660 \mathrm{~km}$ phase boundary (arrows "A1"). We call this type of daughter plume "Type A". The daughter plumes are somewhat smaller than the mother plume in the lower mantle, and horizontally shift away from the mother plume (arrow "A2"). Besides the mother plumes, the diffused return flow by major downwellings ("subducting plates" at both sides of convecting box; arrows "SP") in the shallow part of the lower mantle (a) Case P1500P

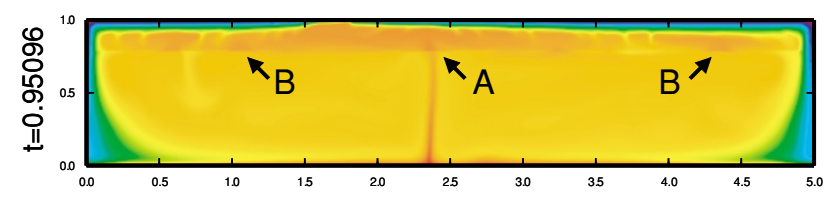

(b) Case P4000P

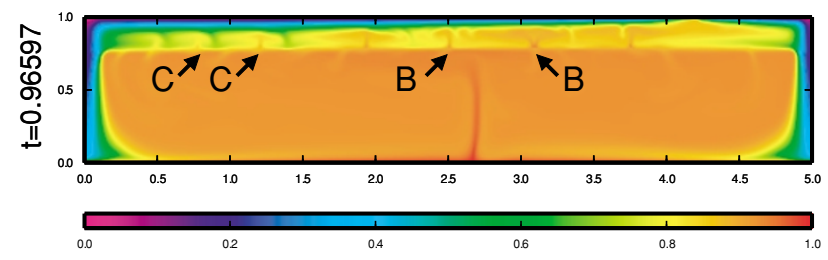

Fig. 3. The same as Fig. 2 for Cases (a) P1500P and (b) P4000P.

passively induces the daughter plumes uprising into the upper mantle (arrow "B"). We call this type of daughter plume "Type B". In both types A and B, the materials in the daughter plumes come form the lower mantle as can be seen from the heating in the daughter plumes by the latent heat release in the vicinity of the $660 \mathrm{~km}$ phase boundary; on the formation of the daughter plumes, the "roots" of the daughter plumes at the $660 \mathrm{~km}$ phase boundary are considerably hotter than the materials just beneath the $660 \mathrm{~km}$ phase boundary.

To see the influence of change of Clausius-Clapeyron slope, in Fig. 3(a), we present a typical convective flow pattern for the Case P1500P where $\hat{\chi}_{660}$ is $-1.5 \mathrm{MPa} / \mathrm{K}$. The slope is at the lower bound of the range that is appropriate for the $660 \mathrm{~km}$ phase boundary. Compared with Case $\mathrm{P} 2500 \mathrm{P}$, the mother plumes in the lower mantle easily penetrate through the $660 \mathrm{~km}$ phase boundary (arrow "A" that indicates Type A). The diffused return flow by subducting plates across the $660 \mathrm{~km}$ phase boundary induces the daughter plumes (arrows "B", i.e., Type B), but is somewhat broader than the daughter plumes in Case P2500P. The convective flow pattern appears to be a single layered convection rather than a double layered convection.

We next present a typical convective flow pattern where $\hat{\chi}_{660}$ is $-4.0 \mathrm{MPa} / \mathrm{K}$ in Fig. 3(b). The slope is at the higher bound of the range that is appropriate for the $660 \mathrm{~km}$ phase boundary. Compared with the above two cases (Case $\mathrm{P} 2500 \mathrm{P}$ and $\mathrm{P} 1500 \mathrm{P}$ ), the mother plume in the lower mantle are more diffuse and weak as a result of the higher temperature in the lower mantle. The mother plumes are completely blocked by the $660 \mathrm{~km}$ phase boundary and hardly penetrate through the $660 \mathrm{~km}$ phase boundary. As a result of this filtering effect, the formation and growth of the small upwelling plumes in the upper mantle originate, independently of the mother plume, so that the small upwelling plumes are not connected to the mother plume in the lower mantle. Namely there are two types in these upwelling plumes; (1) the small plumes (Type B) that occur as a diffused return flow by subducting plates across the $660 \mathrm{~km}$ phase boundary (arrows "B"), (2) the secondary upwelling plumes which occur as a return flow of the secondary downwelling plumes sinking from the base of the lithosphere 
(a) Case P1500P

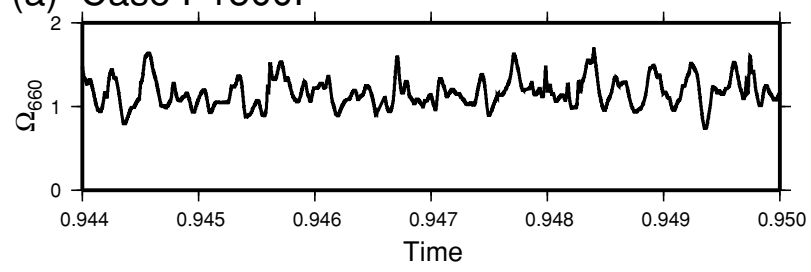

(b) Case P2500P

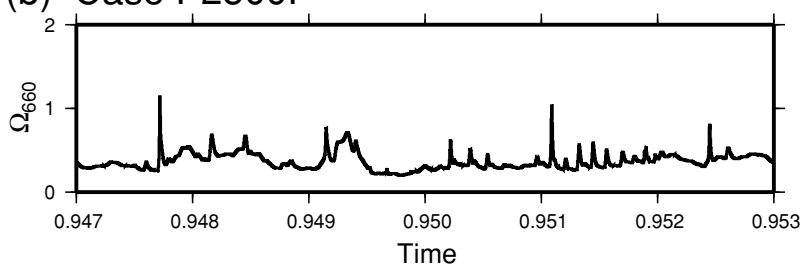

(c) Case P4000P

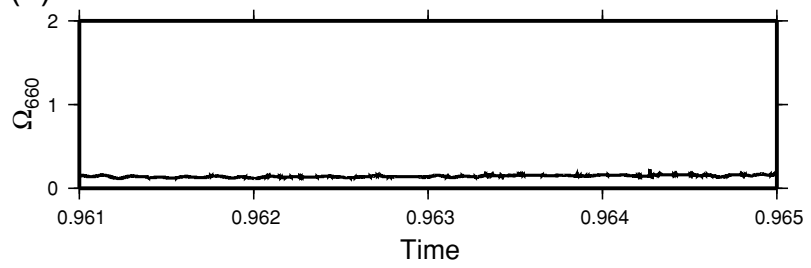

Fig. 4. The time-series of the vertical mass flux diagnosis at the $660 \mathrm{~km}$ phase boundary $\Omega_{660}$ for Cases (a) P1500P, (b) P2500P, and (c) P4000P.

(arrows "C"). We call these secondary upwelling plumes "Type C". Owing to these two types of plumes, the numerous small convection cells confined in the upper mantle develop, so that the horizontal scale of convective flow pattern in the upper mantle is significantly smaller than that in the lower mantle. These convecting features indicate a stronger propensity toward a double layered convection in spite of the existence of subducting plates penetrating into the lower mantle.

Figure 4 shows a time-series of vertical mass flux diagnosis $\Omega_{p h}$ for Series PL-1. The diagnosis for the 660 $\mathrm{km}$ phase boundary $\Omega_{660}$ decreases, that is, the propensity toward the layered convection becomes stronger, as the Clausius-Clapeyron slope is steepened. In Case P1500P (Fig. 4(a)), $\Omega_{660}$ is around 1.0 throughout the run in spite of time-dependent fluctuations. This means that the convective flow is almost unaffected by the $660 \mathrm{~km}$ phase transition. In contrast, for the Case P4000P (Fig. 4(c)), $\Omega_{660}$ is quite low, i.e., about 0.2 or less throughout the run, which means that the effects of the $660 \mathrm{~km}$ phase transition strongly impedes the convective flow across the $660 \mathrm{~km}$ phase boundary.

3.1.2 Weak-plate regime (Series WP-1) To explore the effects of change of convective regimes on the convective feature, we present the results of a series of calculations where $E=\ln 10^{6.5}=14.97$ (Series WP-1 in Table 2). Taking this $E$, the convective flow pattern is on the "weak-plate regime" (Ogawa, 2003). On the weak-plate regime, the lithosphere is frequently damaged both by their own weight and by hot uprising plumes. In Fig. 5, the typical snapshots of convective flow pattern with the $660 \mathrm{~km}$ phase transition are presented for the cases with (a) $\hat{\chi}_{660}=-1.5 \mathrm{MPa} / \mathrm{K}$ (Case P1500W), (b) $\hat{\chi}_{660}=-2.5 \mathrm{MPa} / \mathrm{K}$ (Case P2500W), and (c) $\hat{\chi}_{660}=-4.0 \mathrm{MPa} / \mathrm{K}($ Case $\mathrm{P} 4000 \mathrm{~W})$. (a) Case P1500W
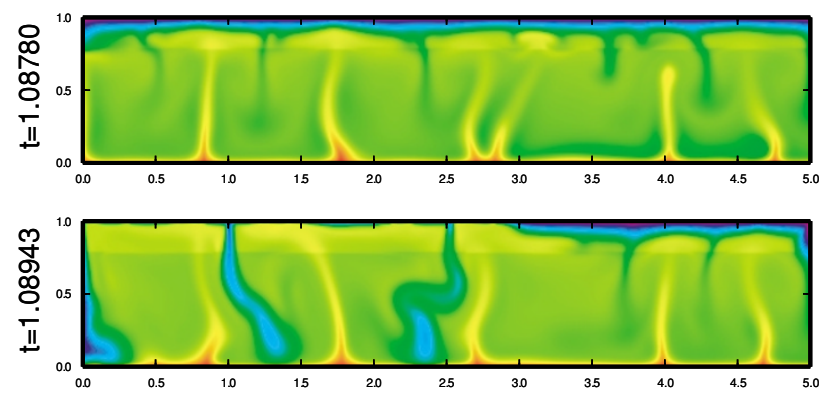

(b) Case P2500W
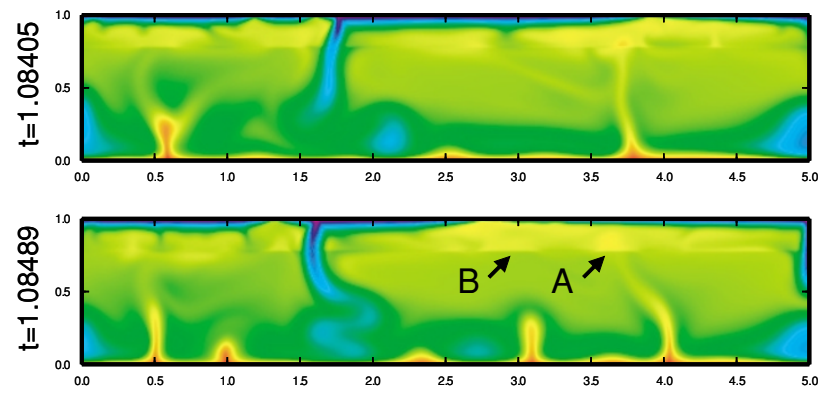

(c) Case P4000W
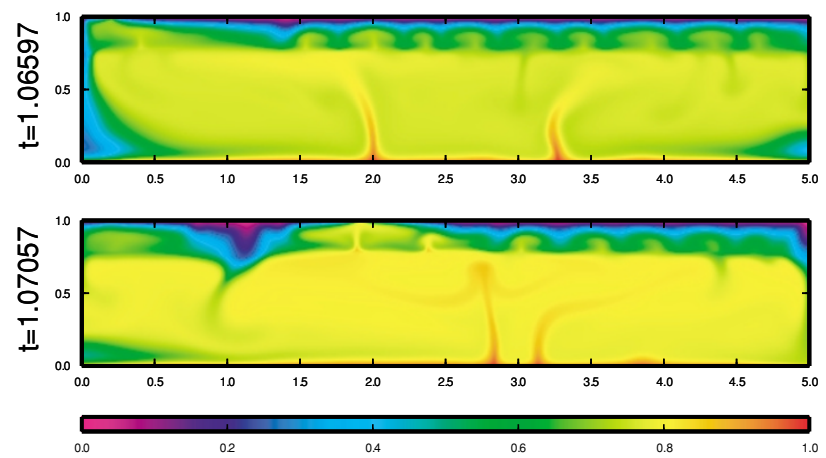

Fig. 5. The same as Fig. 2 for Cases (a) P1500W, (b) P2500W, and (c) P4000W.

The temperature contrast between the plumes and the surrounding lower mantle is larger on the weak-plate regime than that on the plate-like regime (Series PL-1 in Figs. 2 and 3). The upwelling plumes from the lower mantle (i.e., mother plumes) are, therefore, more buoyant on the weak-plate regime than the plumes are on the plate-like regime. This is because the average mantle temperature is lower on the weak-plate regime than the average mantle temperature is on the plate-like regime. Through all the cases, small downwellings from the top thermal boundary layer are blocked by the $660 \mathrm{~km}$ phase transition, but there is a major cold downwelling that penetrates the $660 \mathrm{~km}$ phase boundary. In a case with an intermediate ClausiusClapeyron slope of $\hat{\chi}_{660}=-2.5 \mathrm{MPa} / \mathrm{K}$ (Fig. 5(b)), the daughter plume (arrow "A") and return flow by major cold downwellings in the upper mantle (arrow "B") are too broad and blurred compared with those on the plate-like regime (cf. Fig. 2).

The time-series of vertical mass flux through the $660 \mathrm{~km}$ phase boundary for each Series WP-1 is shown in Fig. 6. 
(a) Case P1500W

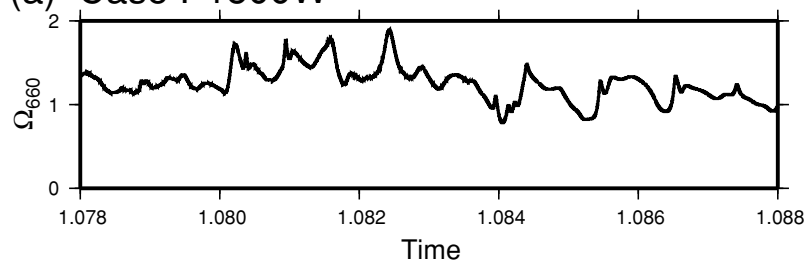

(b) Case P2500W

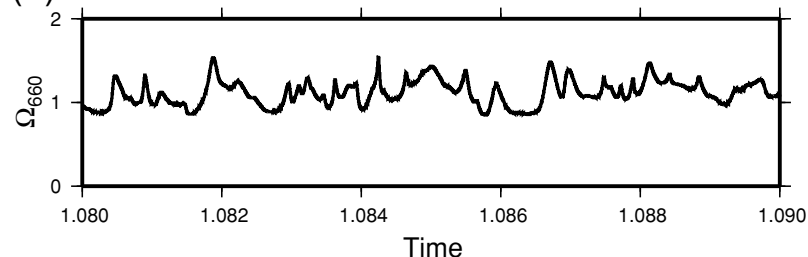

(c) Case P4000W

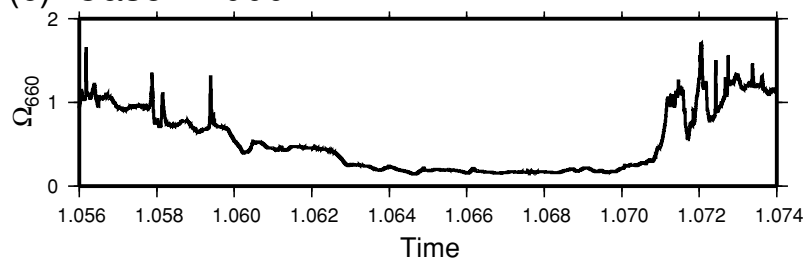

Fig. 6. The same as Fig. 4 for Cases (a) P1500W, (b) P2500W, and (c) P4000W.

We found that, in contrast with the cases of the plate-like regime (Fig. 4), the change of the Clausius-Clapeyron slope searched here less affects the general flow pattern.

3.1.3 Stagnant-lid regime (Series ST-1) We next show a series of calculations where $E=\ln 10^{8.5}=19.57$ (Series ST-1 in Table 2). The convective flow patterns are in the "stagnant-lid regime" (Ogawa et al., 1991; Solomatov, 1995; Ogawa, 2003); the lithosphere behaves as a stagnant (immobile) lid that never subducts. Figure 7 shows the typical snapshots of convective flow patterns for the cases with (a) $\hat{\chi}_{660}=-1.5 \mathrm{MPa} / \mathrm{K}\left(\right.$ Case P1500S), (b) $\hat{\chi}_{660}=-2.5$ $\mathrm{MPa} / \mathrm{K}\left(\right.$ Case P2500S), and (c) $\hat{\chi}_{660}=-4.0 \mathrm{MPa} / \mathrm{K}$ (Case P4000S).

The temperature contrast between the plumes and the surrounding lower mantle is quite smaller on the stagnantlid regime than that on the plate-like regime (Series PL-1 in Figs. 2 and 3) and the weak-plate regime (Series WP-1 in Fig. 5). The mother plumes are, therefore, less buoyant in the stagnant-lid regime because of the higher mantle temperature. The mother plumes somewhat penetrate through the $660 \mathrm{~km}$ phase boundary for the case with the lower Clausius-Clapeyron slopes (arrows "A" in Fig. 7(a)), but are hardly to penetrate through the $660 \mathrm{~km}$ phase boundary for the case with the higher Clausius-Clapeyron slope (Fig. 7(c)). When lower Clausius-Clapeyron slopes are taken (Fig. 7(a)), the secondary downwelling plumes emerging beneath the top thermal boundary layer locally penetrate the $660 \mathrm{~km}$ phase boundary (see arrows "SD"). On the other hand, when higher Clausius-Clapeyron slopes are taken (Fig. 7(c)), the secondary downwelling plumes are completely blocked by the $660 \mathrm{~km}$ phase boundary, so that the small-scale convection restricted in the upper mantle develops. We can recognize that the change of the (a) Case P1500S
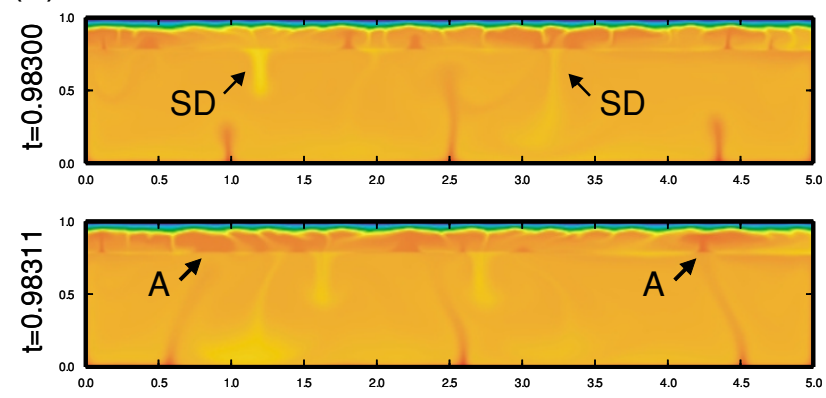

(b) Case P2500S
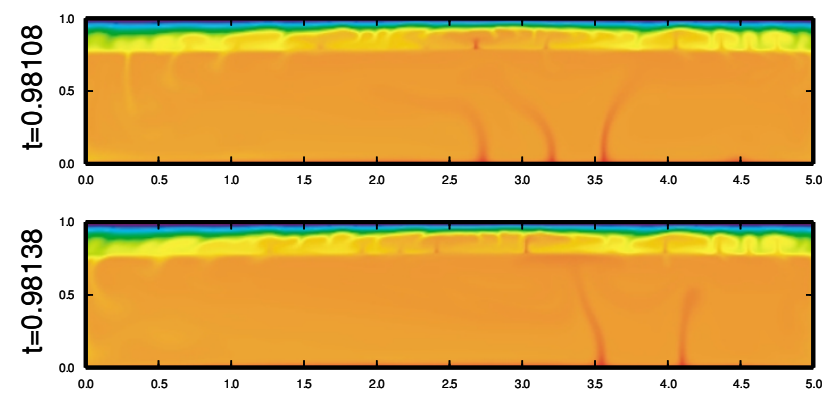

(c) Case P4000S
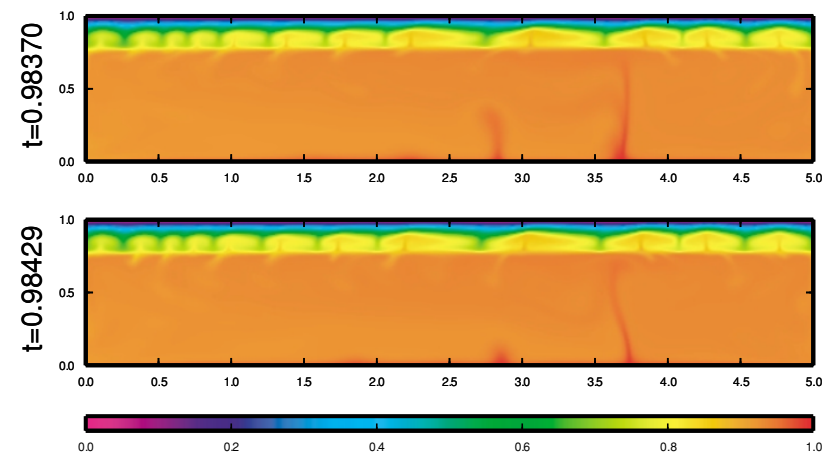

Fig. 7. The same as Fig. 2 for Cases (a) P1500S, (b) P2500S, and (c) P4000S.

Clausius-Clapeyron slope searched here affects the general flow pattern, which is indicated by vertical mass flux diagnosis shown in Fig. 8. When the Clausius-Clapeyron slope is taken to be the lower bound $\left(\hat{\chi}_{660}=-1.5 \mathrm{MPa} / \mathrm{K}\right)$, the convecting features are close to a single layered convection (i.e., $\Omega_{660}$ keeps around 1 in spite of a large fluctuation). In contrast, taking the Clausius-Clapeyron slope of -2.5 $\mathrm{MPa} / \mathrm{K}$ or more, the convective feature are close to a double layered convection (i.e., $\Omega_{660}$ is around 0.1 ).

\subsection{The cases with 660 and $410 \mathrm{~km}$ phase boundaries}

To investigate the effects of inclusion of the exthothermic phase transition at the $410 \mathrm{~km}$ phase boundary on the convective flow pattern, we present the results of a series of calculations where the effects of the $410 \mathrm{~km}$ phase transition is added to the calculations in Series PL-1, WP-1 and ST-1 (Series PL-2, WP-2 and ST-2 in Table 2, respectively). The Clausius-Clapeyron slope at the $410 \mathrm{~km}$ phase boundary is fixed at $\hat{\chi}_{410}=+2.0 \mathrm{MPa} / \mathrm{K}$, which is an intermediate value estimated by high pressure experiments. As the cases with only $660 \mathrm{~km}$ phase boundary, the Clausius-Clapeyron 
(a) Case P1500S

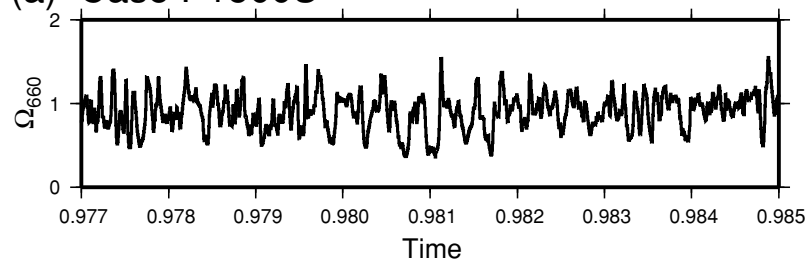

(b) Case P2500S

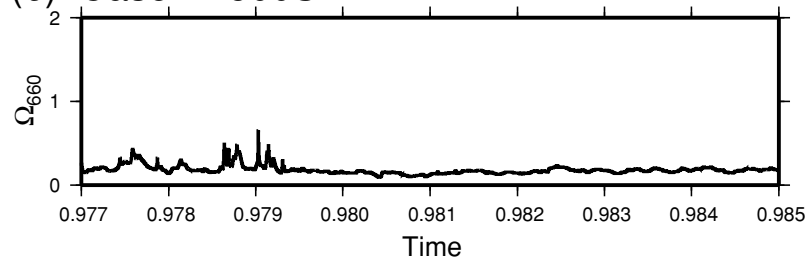

(c) Case P4000S

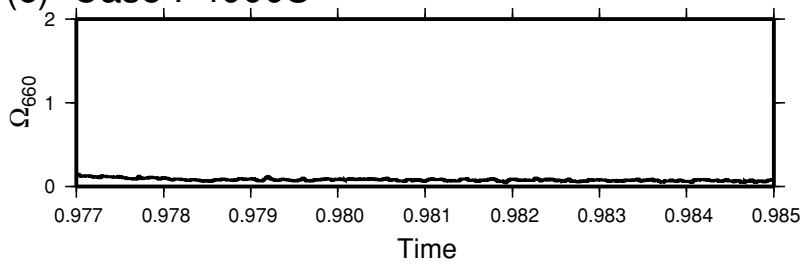

Fig. 8. The same as Fig. 4 for Cases (a) P1500S, (b) P2500S, and (c) P4000S.

slope is chosen three values, $-1.5 \mathrm{MPa} / \mathrm{K},-2.5 \mathrm{MPa} / \mathrm{K}$ and $-4.0 \mathrm{MPa} / \mathrm{K}$ in each series.

3.2.1 Plate-like regime (Series PL-2) Figure 9 shows a time-series of typical convective flow patterns for Case P2520P where $\hat{\chi}_{660}$ is $-2.5 \mathrm{MPa} / \mathrm{K}$. As is observed in Case P2500P (Fig. 2) where only the $660 \mathrm{~km}$ phase boundary is included, the daughter plume, named Type A in Series PL-1, is induced by the mother plumes in the lower mantle (arrows "A"). The daughter plume coming from the $660 \mathrm{~km}$ phase boundary is somewhat impeded at the $410 \mathrm{~km}$ phase boundary probably due to a negative buoyancy force induced by absorption of latent heat at the phase boundary. The secondary downwelling plumes coming from the base of the lithosphere are also blocked at the $410 \mathrm{~km}$ phase boundary due to a positive buoyancy force induced by the latent heat release at the $410 \mathrm{~km}$ phase boundary. The small upwelling plume which occur as a diffused return flow by subducting plates, named Type B in Series PL-1, is also seen in this case.

In Case P1520P where $\hat{\chi}_{660}$ is $-1.5 \mathrm{MPa} / \mathrm{K}$ (Fig. 10(a)), the mother plume in the lower mantle easily penetrates through the $660 \mathrm{~km}$ phase boundary. The daughter plume penetrating through the $660 \mathrm{~km}$ phase boundary is horizontally spread between the $410 \mathrm{~km}$ and $660 \mathrm{~km}$ phase boundaries, and the mantle temperature in the transition zone (410 $\mathrm{km}$ depth to $660 \mathrm{~km}$ depth) increases. In Case P4020P where $\hat{\chi}_{660}$ is $-4.0 \mathrm{MPa} / \mathrm{K}$ (Fig. 10(b)), compared with Case P4000P where only the $660 \mathrm{~km}$ phase boundary is included (Fig. 3(b)), the average temperature in the lower mantle is decreased, because the $410 \mathrm{~km}$ phase transition reduces the effect of the $660 \mathrm{~km}$ phase boundary. We can see that the number of secondary upwelling plumes coming from the $660 \mathrm{~km}$ phase boundary is decreased when com-
Case P2520P
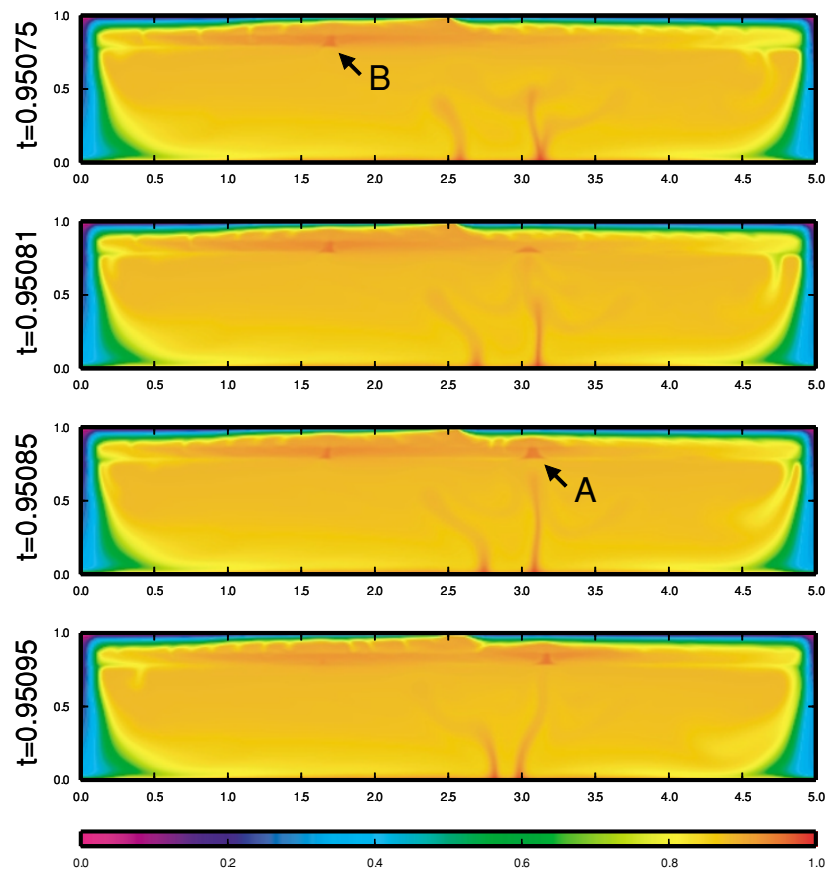

Fig. 9. The time-series of temperature fields for Case P2520P. The non-dimensional elapsed time $t=0.001$ corresponds to $267 \mathrm{Myr}$ in dimensional time.

\section{(a) Case P1520P}

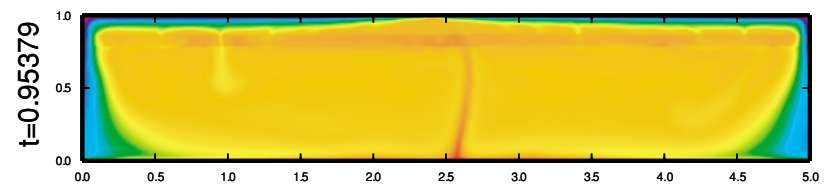

(b) Case P4020P

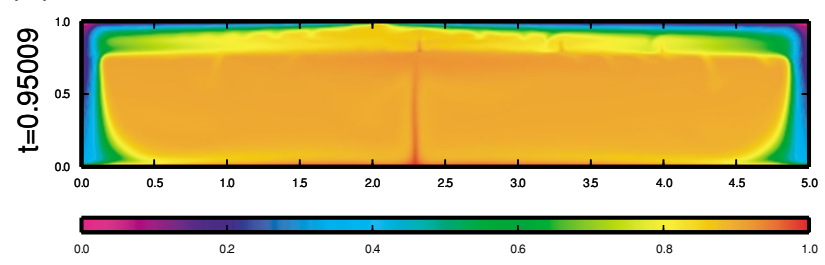

Fig. 10. The same as Fig. 9 for Cases (a) P1520P and (b) 4020P.

pared with Case P4000P. This is because the secondary downwelling plumes originating from the lithosphere are blocked at the $410 \mathrm{~km}$ phase boundary, and hence, the small convective flow cell is hard to develop in the upper mantle.

Shown in Fig. 11 is a time-series of vertical mass flux diagnosis for Series PL-2. The vertical mass flux through the $660 \mathrm{~km}$ phase boundary ( $\Omega_{660}$ shown by the solid line) is higher in Series PL-2 than in Series PL-1 only with the 660 km phase boundary, especially compared with Case P2500P (Fig. 4(b)) and P2520P (Fig. 11(b)). This implies that, as we can expect, the $410 \mathrm{~km}$ phase boundary enhances mass exchange between the upper and lower mantle on the platelike regime. The vertical mass flux through the $410 \mathrm{~km}$ phase boundary ( $\Omega_{410}$ shown by dashed line) is less affected by the change of the Clausius-Clapeyron slope of the 660 
(a) Case P1520P

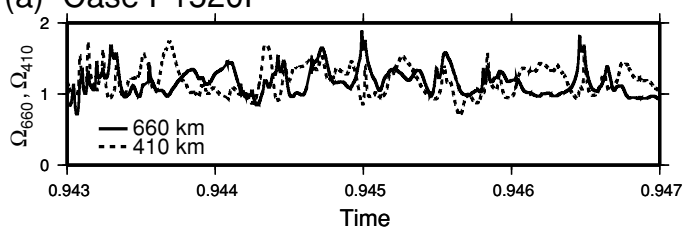

(b) Case P2520P

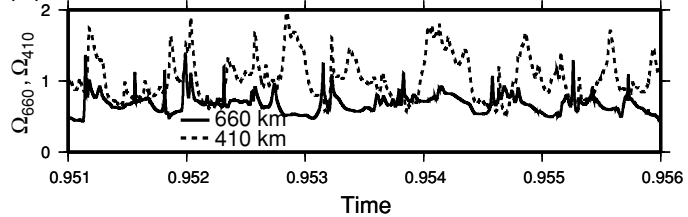

(c) Case P4020P

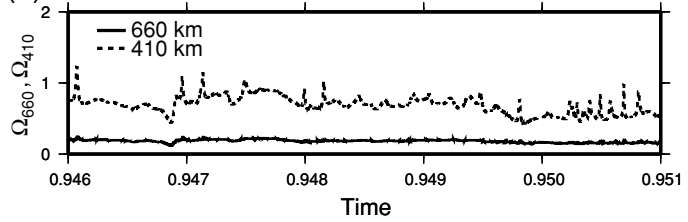

Fig. 11. The time-series of the vertical mass flux diagnosis $\Omega_{p h}$ for Cases (a) P1520P, (b) P2520P, and (c) P4020P. The solid lines and the dashed lines are the $\Omega_{p h}$ at the $660 \mathrm{~km}$ and the $410 \mathrm{~km}$ phase boundaries, respectively.

(a) Case P1520W
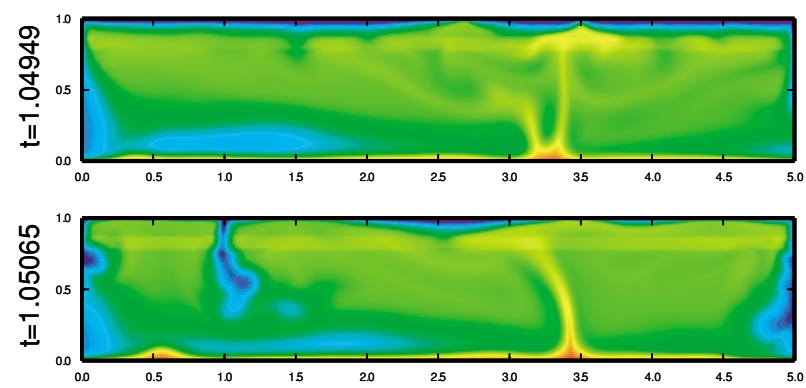

(b) Case P2520W
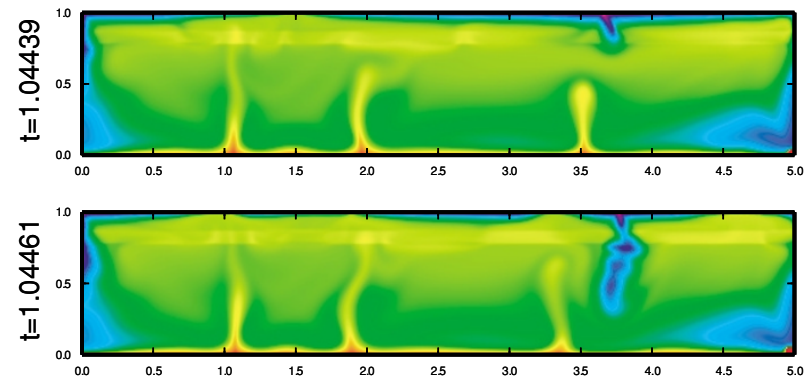

(c) Case P4020W
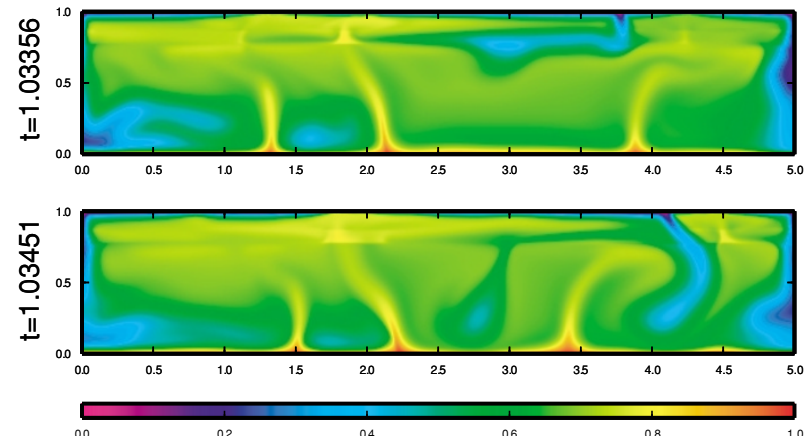

Fig. 12. The same as Fig. 9 for Cases (a) P1520W, (b) P2520W, and (c) P4020W.

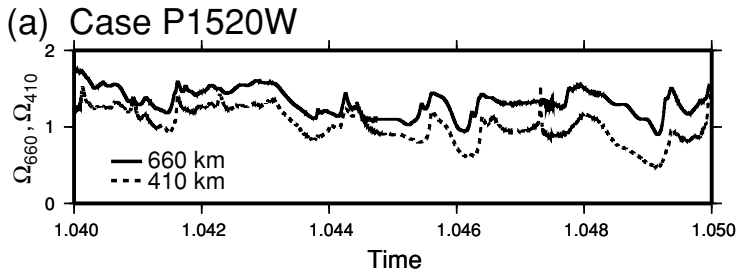

(b) Case P2520W
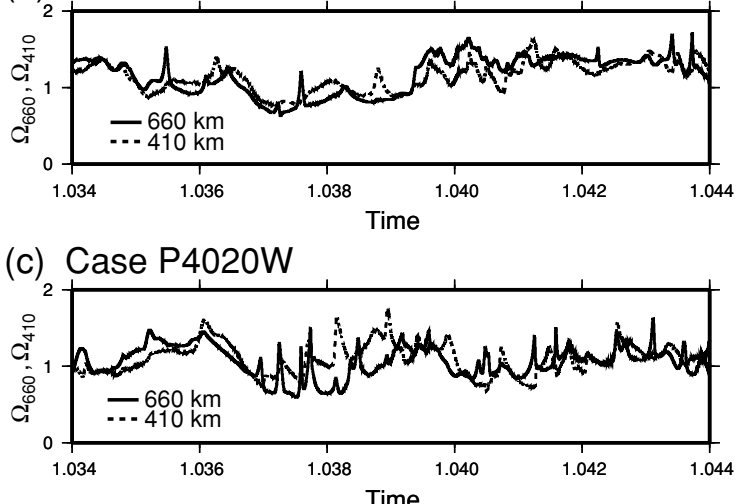

Fig. 13. The same as Fig. 11 for Cases (a) P1520W, (b) P2520W, and (c) P4020W.

(a) Case P1520S
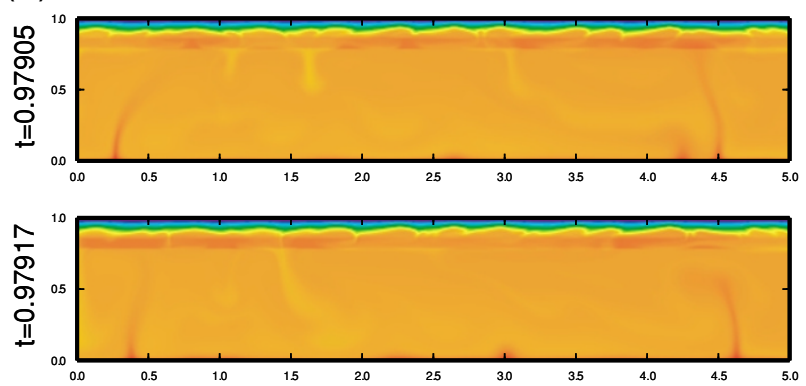

(b) Case P2520S
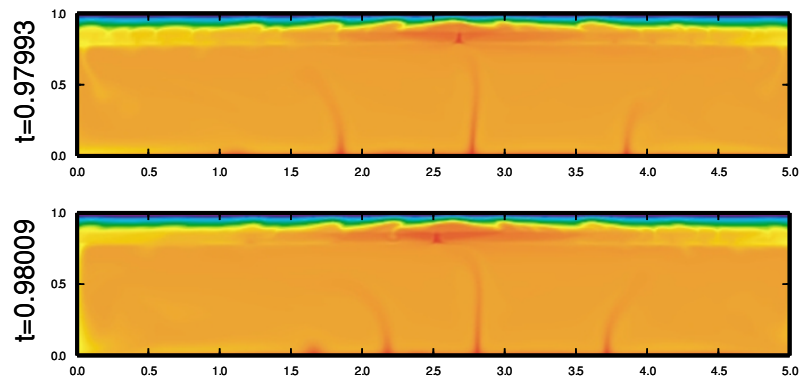

(c) Case P4020S
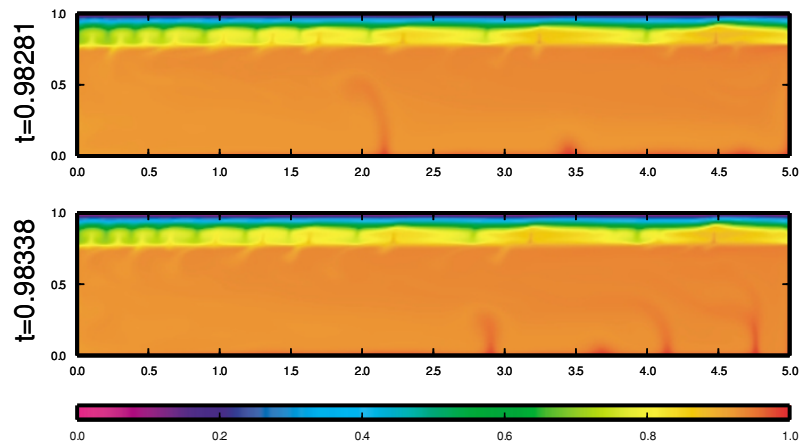

Fig. 14. The same as Fig. 9 for Cases (a) P1520S, (b) P2520S, and (c) P4020S. 
(a) Case P1520S

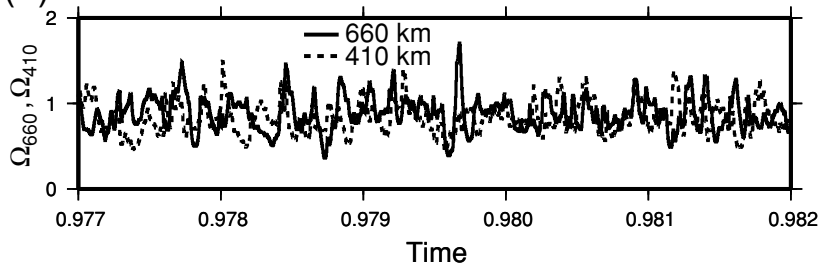

(b) Case P2520S

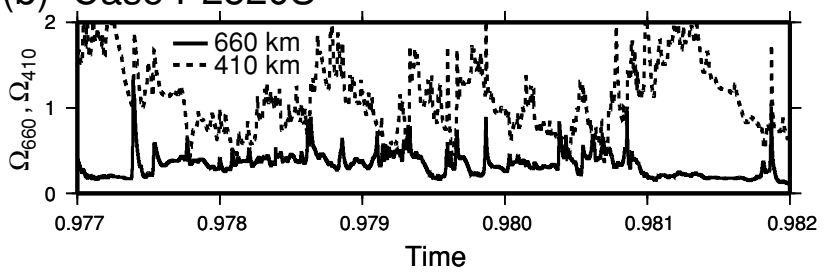

(c) Case P4020S

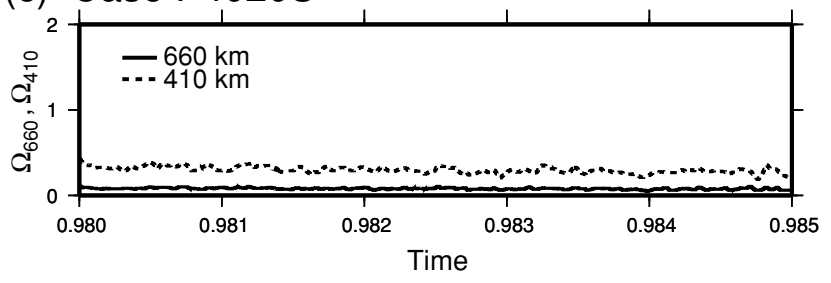

Fig. 15. The same as Fig. 11 for Cases (a) P1520S, (b) P2520S, and (c) P4020S.

$\mathrm{km}$ phase boundary rather than vertical mass flux through the $660 \mathrm{~km}$ phase boundary. We recognized that the high $\Omega_{410}$ is a result of active convection within the upper mantle.

3.2.2 Weak-plate and stagnant-lid regimes (Series WP-2 and ST-2) Figure 12 shows the typical snapshots of convective flow pattern for Series WP-2 in Table 2; the cases with (a) $\hat{\chi}_{660}=-1.5 \mathrm{MPa} / \mathrm{K}$ (Case P1520W), (b) $\hat{\chi}_{660}=-2.5 \mathrm{MPa} / \mathrm{K}\left(\right.$ Case P2520W), and (c) $\hat{\chi}_{660}=-4.0$ $\mathrm{MPa} / \mathrm{K}$ (Case $\mathrm{P} 4020 \mathrm{~W}$ ). The effect of $410 \mathrm{~km}$ phase transition on the convective flow pattern is not so conspicuous in Series WP-2. This is obvious from the vertical mass flux diagnosis (Fig. 13). Even when the higher ClausiusClapeyron slope is assumed at the $660 \mathrm{~km}$ phase boundary (Fig. 13(b)), the $\Omega_{660}$ and $\Omega_{410}$ keep around 1 because the mass exchange through the $660 \mathrm{~km}$ phase boundary is active owing to the frequent major downwellings from the top thermal boundary layer.

Shown in Fig. 14 are the typical snapshots of convective flow pattern for Series ST-2 in Table 2; the cases with (a) $\hat{\chi}_{660}=-1.5 \mathrm{MPa} / \mathrm{K}$ (Case P1520S), (b) $\hat{\chi}_{660}=-2.5$ $\mathrm{MPa} / \mathrm{K}\left(\right.$ Case P2520S), and (c) $\hat{\chi}_{660}=-4.0 \mathrm{MPa} / \mathrm{K}$ (Case P4020S). A comparison of Series ST-2 (Fig. 14) with Series ST-1 (Fig. 7) shows that the $410 \mathrm{~km}$ phase boundary has only minor effects on the mass exchange between the upper mantle and the lower mantle on the stagnant-lid regime, which is confirmed by the vertical mass flux diagnosis (Fig. 15).

\section{Discussion}

\subsection{Three types of small upwelling plumes in the upper} mantle

On the plate-like regime, we found three possible types of small upwelling plumes in the upper mantle (Fig. 16):

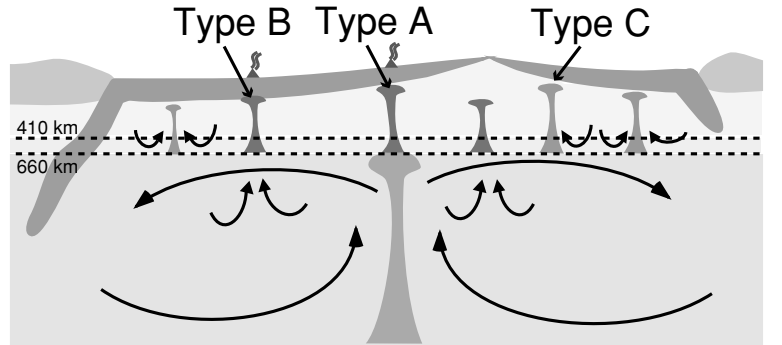

Fig. 16. A cartoon showing the three possible types (Types A, B, and C) of upwelling plumes in the upper mantle obtained from our numerical results.

(1) The first type, named Type A, is the secondary plumes directly derived from the upwelling plume from the lower mantle that penetrates through the $660 \mathrm{~km}$ phase boundary. (2) The second type, named Type B, is the passive upwellings from the shallow parts of the lower mantle that penetrate through the $660 \mathrm{~km}$ phase boundary due to the diffused return flow by continuously subducting plates. (3) The third type, named Type $\mathrm{C}$, is the secondary upwelling plumes originating from the $660 \mathrm{~km}$ phase boundary caused by the development of the small-scale convection cells confined in the upper mantle. We found that the plumes penetrating through the $660 \mathrm{~km}$ phase boundary are spread horizontally between the $410 \mathrm{~km}$ and $660 \mathrm{~km}$ phase boundaries. This indicates that the $410 \mathrm{~km}$ phase boundary affect the thermal structure in the transition zones.

As we have expected, the possibility of Type A tends to increase when the Clausius-Clapeyron slope at $660 \mathrm{~km}$ phase boundary is the lower bound, because of the nature of the weaker barrier at the $660 \mathrm{~km}$ phase boundary. From the calculations searched here, the Type B appears to be a general feature irrespective of the strength of ClausiusClapeyron slope at the $660 \mathrm{~km}$ phase boundary, although the feature is somewhat defuse when the strength of ClausiusClapeyron slope is the lowermost (Fig. 10(a)). The Type $\mathrm{C}$ becomes more likely when the Clausius-Clapeyron slope at the $660 \mathrm{~km}$ phase boundary is taken to be higher bound, because the secondary downwelling plumes sinking from the base of the lithosphere are blocked at the $660 \mathrm{~km}$ phase boundary, so that the small convection cells in the upper mantle develop.

The upwelling plumes and/or the broad return flow from the lower mantle throughout the $660 \mathrm{~km}$ phase boundary have been observed in the previous models with the moderately temperature-dependent viscosity (i.e., the viscosity contrast across the convecting layer is $10^{3}$ ) (Nakakuki et al., 1994; Zhong and Gurnis, 1994). Indeed, both of the types A and B observed on the plate-like regime can be seen on the weak-plate regime (Figs. 5 and 12) because they essentially occur owing to the mass exchange across the $660 \mathrm{~km}$ phase boundary. Their plumes on the weak-plate regime are, however, somewhat too broad and blurred compared with those on the plate-like regime. The formation of numerous small upwelling plumes originating at the $660 \mathrm{~km}$ phase boundary is seen in models with a synthetic viscosity jump across the $660 \mathrm{~km}$ phase boundary (Steinbach and 
Yuen, 1997). They concluded that a major effect of the high viscosity in the lower mantle is the stabilization of upwelling plumes in the lower mantle, and the impingement of these plumes at the $660 \mathrm{~km}$ phase boundary causes the development of secondary upwelling plumes to rise into the upper mantle. It is significant that these kinds of plumes in the upper mantle are reproduced by our mantle convection models without such a viscosity jump across the $660 \mathrm{~km}$ phase boundary. Three types of upwelling plumes observed in our results have been found in the previous models with a synthetic low-viscosity zone under $660 \mathrm{~km}$ phase boundary ("second asthenosphere") (Cserepes and Yuen 1997, 2000; Cserepes et al., 2000). They concluded that the influence of the second asthenosphere is important in inducing the convecting layering and the "mid-mantle plumes" (corresponding to Type B in our study) that have no root in the deep lower mantle. A possibility of the existence of the second asthenosphere has recently argued from recent geoid inversion studies (Kido and Čadek, 1997; Kido et al., 1998; Kido and Yuen, 2000). The important point of our study is that the existence of three types of plume is shown by mantle convection models with self-consistently moving and subducting plates, and with the second asthenosphere that is self-consistently included by the temperature-, and pressure-dependent viscosity (Eq. (10)).

Using a numerical model, King and Ritsema (2000) suggested that some hotspot volcanisms in the south American and African plates may originate in the upper mantle by the small-scale convection at the edges of thick continental cratons and may not originate from the deep lower mantle. Our numerical results, however, suggest that the secondary upwelling plumes can originate at the $660 \mathrm{~km}$ phase boundary, even if a specific horizontal density heterogeneity such as thick cratons does not exist in the upper mantle. The formation of the secondary upwelling plumes in the upper mantle is consistent with the fact that numerous hotspot-plumes on the Pacific and the African plates, and some isolated large hotspot-plumes, that is, the Hawaii hotspot, Caroline hotspot, etc., are located away from the center of the low seismic velocity regions in the lower mantle (e.g., Masters et al., 1999; Mégnin and Romanowicz, 2000).

Some global tomographic images with high-resolution have recently suggested that main hotspot-plumes might come from the shallow parts of the lower mantle, and are not hindered at the upper/lower mantle boundary, for example, Hawaii, Iceland and East Africa (Bijwaard et al., 1998; Rhodes and Davies, 2001; Zhao, 2001), Afar, Society, Crozet, Kerguelen and Iceland (Rhodes and Davies, 2001) and Yellowstone hotspots (Bijwaard et al., 1998). In our numerical results, the small upwelling plumes of Types A and B may be the most-likely candidate for such small plumes manifested as the hotspot-plumes because these plumes have root in the lower mantle.

From isotope studies, the ocean island basalts (OIBs) (e.g., Hawaii, Kerguelen, St. Helena, Society hotspot) tend to be enriched in incompatible elements relative to midocean ridge basalts (MORB) (e.g., Hofmann, 1997; Turcotte and Schubert, 2002). Most geochemists infer that there is a stratification of chemical compositions in the man- tle and the OIBs come from a primordial reservoir in the deep mantle, in contrast with the homogeneneous upper mantle reservoir that is the source of MORBs. Because the upwelling plumes in the lower mantle may entrain their materials in the upper-most lower mantle, they can be a possible candidate for the source region of OIBs (Allègre and Turcotte, 1985; White, 1985). Such a small upwelling in the upper mantle may correspond to the upwelling plumes of Type A or B obtained from our numerical calculations.

To summarize, an image obtained from our numerical model suggests that the thermal and substantial links between the upwelling plume coming from the lower mantle and the small-scale plumes in the upper mantle originating from around the $660 \mathrm{~km}$ phase boundary layer may be natural consequences in the mantle convection with moving and subducting plates on the plate-like regime. These aspects have not been appreciated in the past numerical modeling with a self-consistent manner.

\subsection{Comments on the effects on the estimate of plume heat flow}

According to a widely accepted paradigm or assumption in geophysics, (1) all of the heat transported by mantle plumes directly comes from CMB, and (2) all of the heat transported by mantle plumes can be well estimated from observations of topographic swells under the major hotspots (so-called, hotspot-swells) on the Earth's surface (e.g., Davies, 1999). Under these assumptions, the volumes of hotspot-swells have been used to estimate the heat flux coming from the thermal boundary layer at the CMB (hereafter "CMB heat flow") (e.g., Davies, 1988; Sleep, 1990; Hill et al., 1992; Davies and Richards, 1992). According to the estimate by Sleep (1990), the total amount of heat transported by typical hotspot plumes (hereafter "plume heat flow") to the outside space of the Earth is $2.3 \mathrm{TW}$, that is, only $5 \%$ of the total amount of heat that the Earth is losing, i.e., 44.3 TW (Pollack et al., 1993). This is the lowest value of the estimated CMB heat flow, around $2 \sim 12$ TW, suggested by the power requirements of the geodynamo (e.g., Braginsky and Roberts, 1995; Buffett, 2003), and the thermal history of the core (e.g., Davies, 1988, 1999).

Our study suggests that the upwelling plumes of Types A and B may be the most-likely candidate for the hotspotplumes. By contrast, Type $\mathrm{C}$ may be the secondary plumes due to small-scale convection beneath the lithosphere (e.g., Richter and Parsons, 1975; Buck, 1985), which is likely to hardly express as a hotspot-swells (Malamud and Turcotte, 1999). If some fraction of the hotspot plumes observed on the surface comes from passive upwelling, not from CMB, due to the diffused return flow by subducting plates (Type $\mathrm{B})$ or from the secondary upwelling originating from the $660 \mathrm{~km}$ phase boundary (Type C), then the inferred plume heat flow and CMB heat flow may be overestimated because of the assumption (1). On the other hand, if the heat coming from the lower mantle by upwelling plume of Type A horizontally spread in the upper mantle, then the estimates of plume heat flow and CMB heat flow may be obscure, because all of the mantle plumes might not directly come from the CMB. The assumption (1) is, thereby, rather suspicious. This might be the reason why, if the assumption (2) is correct, the $\mathrm{CMB}$ heat flow estimated by plume heat flow is the 
lowest value of the CMB heat flow suggested by the power requirements of the geodynamo and the thermal history of the core. Namely it would not make sense to assume that the sizes of hotspot-swells can be used to estimate the heat flux coming from the thermal boundary layer at the CMB.

\section{Conclusions}

We have studied the effects of phase on mantle convection with self-consistently moving and subducting plates. We found that the propensity to layering on the plate-like regime are stronger than those on the weak-plate regime both in the cases with only $660 \mathrm{~km}$ phase transition and with $660 \mathrm{~km}$ and $410 \mathrm{~km}$ phase transitions.

On the weak-plate regime, the downwelling plumes from the top thermal boundary layer and the upwelling plumes from the bottom thermal boundary layer are generally buoyant enough to penetrate the $660 \mathrm{~km}$ phase boundary, irrespective of the strength of the Clausius-Clapeyron slope of the $660 \mathrm{~km}$ phase transition searched here. On the other hand, on the plate-like regime, the moving plates continuously subduct and penetrate into the lower mantle along the side of convecting vessel, irrespective of the strength of the Clausius-Clapeyron slope. In the actual Earth's mantle, however, some subducting plates are deformed at the $660 \mathrm{~km}$ phase boundary (e.g., Fukao et al., 2001). This differs from our results on the Plate-like regime, because the reflective condition, not the periodic boundary condition, is applied to the sidewalls in our Cartesian models. In fact, on the weak-plate regime where the highly viscous downwelling plumes subduct everywhere along the top thermal boundary layer, the downwelling plumes are often deformed at the $660 \mathrm{~km}$ phase boundary, but eventually subduct into the lower mantle (Figs. 5 and 12). In contrast with the subducting plates, as the Clausius-Clapeyron slope is steepened, the upwelling plumes from the bottom thermal boundary layer are less buoyant owing to the increase of average mantle temperature. In consequence, they are hard to penetrate through the $660 \mathrm{~km}$ phase boundary. This result suggests that, on the plate-like regime, the strength of Clausius-Clapeyron slope at the $660 \mathrm{~km}$ phase boundary may provide one of the sensitive keys to understand the thermal and substantial links between the upwelling plumes originating from the lower mantle and small-scale upwelling plumes in the upper mantle.

Acknowledgments. We thank two reviewers for their careful reviews and critical comments. D. A. Yuen, S. Honda, and M. Ogawa gave us their valuable comments. P. J. Tackley provided us with his convection code STAG3D. Calculations were carried out on the computer facilities of the Earthquake Information Center, Earthquake Research Institute (ERI), University of Tokyo. Most of the figures attached were produced using the Generic Mapping Tools (GMT) released by P. Wessel and W. H. F. Smith (1998). M. Y. was financially supported by the Japan Society for the Promotion of Science (JSPS) Research Fellowship at ERI from 2000 to 2003. This study was partly supported by the Grand-in-Aid for Scientific Research (JSPS Fellows, \#12-01228) from the Ministry of Education, Culture, Sports, Science and Technology, Japan.

\section{References}

Akaogi, M. and E. Ito, Refinement of enthalpy measurement of $\mathrm{Mg}_{2} \mathrm{SiO}_{3}$ perovskite and negative pressure-temperature slopes for perovskiteforming reactions, Geophys. Res. Lett., 20, 1839-1842, 1993.
Akaogi, M., E. Ito, and A. Navrotsky, Olivine-modified spinel-spinel transitions in the system $\mathrm{Mg}_{2} \mathrm{SiO}_{4}-\mathrm{Fe}_{2} \mathrm{SiO}_{4}$ : Calorimetric measurements, thermochemical calculations, and geophysical applications, J. Geophys. Res., 94, 15671-15685, 1989.

Allègre, C. J. and D. L. Turcotte, Geodynamic mixing in the mesosphere boundary layer and the origin of oceanic islands, Geophys. Res. Lett., 12, 207-210, 1985.

Bercovici, D., Generation of plate tectonics from lithosphere-mantle flow and void-volatile self-lubrication, Earth Planet. Sci. Lett., 154, 139151, 1998.

Bijwaard, H. and W. Sparkmann, Tomographic evidence for a narrow whole mantle plume below Iceland, Earth Planet. Sci. Lett., 166, $121-$ 126, 1999.

Bijwaard, H., W. Sparkmann, and E. R. Engdahl, Closing the gap between regional and global travel time tomography, J. Geophys. Res., 103, 30055-30078, 1998.

Bina, C. R. and G. Helffrich, Phase transition Clapeyron slopes and transition zone seismic discontinuity topography, J. Geophys. Res., 99, 15853-15860, 1994.

Braginsky, S. I. and P. H. Roberts, Equations governing convection in Earth's core and the geodynamo, Geophys. Astrophys. Fluid Dyn., 79, 1-97, 1995.

Brunet, D. and P. Machetel, Large-scale tectonic features induced by mantle avalanches with phase, temperature, and pressure lateral variations of viscosity, J. Geophys. Res., 103, 4929-4945, 1998.

Brunet, D. and D. A. Yuen, Mantle plumes pinched in the transition zone, Earth Planet. Sci. Lett., 178, 13-27, 2000.

Buck, W. R., When does small-scale convection begin beneath oceanic lithosphere?, Nature, 313, 775-777, 1985.

Buffett, B. A., The thermal state of Earth's core, Science, 299, 1675-1677, 2003.

Bunge, H.-P., M. A. Richards, and J. R. Baumgardner, A sensitivity study of three-dimensional spherical mantle convection at $10^{8}$ Rayleigh number: Effects of depth-dependent viscosity, heating mode, and an endothermic phase change, J. Geophys. Res., 102, 11991-12007, 1997.

Chopelas, A., R. Boehler, and T. Ko, Thermodynamics of $\gamma-\mathrm{Mg}_{2} \mathrm{SiO}_{4}$

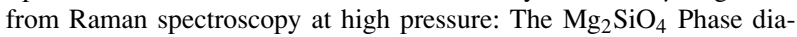
gram, Phys. Chem. Miner., 21, 351-359, 1994.

Christensen, U. R., Effects of phase transitions on mantle convection, Annu. Rev. Earth Planet. Sci., 23, 65-87, 1995.

Christensen, U. R. and D. A. Yuen, Layered convection induced by phase transitions, J. Geophys. Res., 90, 10291-10300, 1985.

Cserepes, L. and D. A. Yuen, Dynamical consequences of mid-mantle viscosity stratification on mantle flows with an endothermic phase transition, Geophys. Res. Lett., 24, 181-184, 1997.

Cserepes, L. and D. A. Yuen, On the possibility of a second kind of mantle plume, Earth Planet. Sci. Lett., 183, 61-71, 2000.

Cserepes, L., D. A. Yuen, and B. Schroeder, Effect of the mid-mantle viscosity and phase-transition structure on 3D mantle convection, Phys. Earth Planet. Int., 118, 135-148, 2000.

Davies, G. F., Ocean bathymetry and mantle convection. 1. Large-scale flow and hotspots, J. Geophys. Res., 93, 10467-10480, 1988.

Davies, G. F., Dynamic Earth: Plates, Plumes and Mantle Convection, Cambridge Univ. Press, pp. 458, Cambridge, U.K., 1999.

Davies, G. F. and M. A. Richards, Mantle convection, J. Geol., 100, 151206, 1992.

Duncan, R. A. and M. A. Richards, Hotspot, mantle plumes, flood basalts, and true polar wander, Rev. Geophys., 29, 31-50, 1991.

Foulger, G. R. and D. G. Pearson, Is Iceland underlain by a plume in the lower mantle? Seismology and helium isotopes, Geophys. J. Int., 145 , F1-F5, 2001.

Foulger, G. R., M. J. Pritchard, B. R. Julian, J. R. Evans, R. M. Allen, G. Nolet, W. J. Morgan, B. H. Bergsson, P. Erlendsson, S. Jakobsdottir, S. Ragnarsson, R. Stefansson, and K. Vogfjord, The seismic anomaly beneath Iceland extends down to the mantle transition zone and no deeper, Geophys. J. Int., 142, F1-F5, 2000.

Foulger, G. R., M. J. Pritchard, B. R. Julian, J. R. Evans, R. M. Allen, G. Nolet, W. J. Morgan, B. H. Bergsson, P. Erlendsson, S. Jakobsdottir, S. Ragnarsson, R. Stefansson, and K. Vogfjord, Seismic tomography shows that upwelling beneath Iceland is confined to the upper mantle, Geophys. J. Int., 146, 504-530, 2001.

Fukao, Y., S. Widiyantoro, and M. Obayashi, Stagnant slabs in the upper and lower mantle transition zone, Rev. Geophys., 39, 291-323, 2001.

Garnero, E. J., J. Revenaugh, Q. Williams, T. Lay, and L. H. Kellogg, Ultralow Velocity zone at the core-mantle boundary, in The Core-mantle Boundary Region, edited by, M. Gurnis, M. E. Wysession, E. Knittle 
and B. A. Buffett, volume 28 of Geodynamics series, Amer. Geophys. Union., Washington, DC., 1998.

Hill, R. I., I. H. Campbell, and G. F. Davies, Mantle plumes and continental tectonics, Science, 256, 186-193, 1992.

Hofmann, A. W., Mantle chemistry, the message from oceanic volcanism, Nature, 385, 219-229, 1997.

Honda, S., D. A. Yuen, S. Balachandar, and D. Reuteler, Threedimensional instabilities of mantle convection with multiple phase transitions, Science, 259, 1308-1311, 1993.

Ita, J. and S. D. King, Sensitivity of convection with an endothermic phase change to the form of the governing equations, initial conditions, boundary conditions, and equation of state, J. Geophys. Res., 99, 1591915938, 1994.

Ito, E. and E. Takahashi, Postspinel transformations in the system $\mathrm{Mg}_{2} \mathrm{SiO}_{4}-\mathrm{Fe}_{2} \mathrm{SiO}_{4}$ and some geophysical implications, J. Geophys. Res., 94, 10637-10646, 1989.

Ito, E., M. Akaogi, L. Topor, and A. Navrotsky, Negative pressuretemperature slopes for reactions forming $\mathrm{MgSiO}_{3}$ perovskite from calorimetry, Science, 249, 1275-1278, 1990.

Katsura, T. and E. Ito, The system $\mathrm{Mg}_{2} \mathrm{SiO}_{4}-\mathrm{Fe}_{2} \mathrm{SiO}_{4}$ at high pressures and temperatures: Precise determination of stabilities of olivine, modified spinel, and spinel, J. Geophys. Res., 94, 15663-15670, 1989.

Kido, M. and O. Čadek, Inferences of viscosity from the oceanic geoid: Indication of a low viscosity zone below the $660-\mathrm{km}$ discontinuity, Earth Planet. Sci. Lett., 151, 125-137, 1997.

Kido, M. and D. A. Yuen, The role played by a low viscosity zone under a $660 \mathrm{~km}$ discontinuity in regional mantle layering, Earth Planet. Sci. Lett., 181, 573-583, 2000.

Kido, M., D. A. Yuen, O. Cadek, and T. Nakakuki, Mantle viscosity derived by genetic algorithm using oceanic geoid and seismic tomography for whole-mantle versus blocked-flow situations, Phys. Earth Planet. Inter., 107, 307-326, 1998.

King, S. D. and J. J. Ita, Effect of Slab rheology on mass transport across a phase transition boundary, J. Geophys. Res., 100, 20,211-20,222, 1995.

King, S. D. and J. Ritsema, African hot spot volcanism: Small-scale convection in the upper mantle beneath cratons, Science, 290, 1137-1140, 2000.

Larson R. L., Latest pulse of Earth: Evidence for a mid-Cretaceous superplume, Geology, 19, 547-550, 1991.

Loper, D. E. and F. D. Stacey, The dynamical and thermal structure of deep mantle plumes, Phys. Earth Planet. Int., 33, 304-317, 1983.

Machetel, P. and P. Weber, Intermittent layered convection in a model mantle with an endothermic phase change at $670 \mathrm{~km}$, Nature, 350, 55$57,1991$.

Malamud, B. D. and D. L. Turcotte, How many plumes are there?, Earth Planet. Sci. Lett., 174, 113-124, 1999.

Masters, G., H. Bolton, and G. Laske, Joint seismic tomography for $\mathrm{p}$ and s velocities: How pervasive are chemical anomalies in the mantle?, Eos. Trans. AGU, 80, Spring Meet. Suppl., S14, 1999.

McKenzie, D. and M. J. Bickle, The volume and composition of melt generated by extension of the lithosphere, J. Petrol., 29, 625-679, 1988.

McKenzie, D. P. and R. K. O'Nions, Mantle reservoirs and oceanic island basalts, Nature, 301, 229-231, 1983.

Mégnin, C. and B. Romanowicz, The three-dimensional shear velocity structure of the mantle from the inversion of body, surface and highermode waveforms, Geophys. J. Int., 143, 709-728, 2000.

Monnereau, M. and M. Rabinowicz, Is the $670 \mathrm{~km}$ phase transition able to layer the Earth's convection in a mantle with depth-dependent viscosity?, Geophys. Res. Lett., 23, 1001-1004, 1996.

Morgan, W. J., Convection plumes in the lower mantle, Nature, 230, 4243, 1971.

Morgan, W. J., Plate motions and deep mantle convection, Geol. Soc. Am. Man., 132, 7-22, 1972.

Nakakuki, T. and H. Fujimoto, Interaction of the upwelling plume with the phase and chemical boundaries-Effects of the pressure-dependent viscosity-, J. Geomag. Geoelectr., 46, 587-602, 1994.

Nakakuki, T., H. Sato, and H. Fujimoto, Interaction of the upwelling plume with the phase and chemical boundary at the $670 \mathrm{~km}$ discontinuity: Effects of temperature-dependent viscosity, Earth Planet. Sci. Lett., 121, 369-384, 1994.

Nataf, H.-C., Seismic imaging of mantle plumes, Annu. Rev. Earth Planet. Sci., 28, 391-417, 2000.

Ogawa, M., Plate-like regime of a numerically modeled thermal convection in a fluid with temperature-, pressure-, and stress-history-dependent viscosity, J. Geophys. Res., 108, 2067, doi:10.1029/2000JB000069, 2003.
Ogawa, M. and H. Nakamura, Thermochemical regime of the early mantle inferred from numerical models of the coupled magmatism-mantle convection system with the solid-solid phase transitions at depths around $660 \mathrm{~km}$, J. Geophys. Res., 103, 12161-12180, 1998.

Ogawa, M., G. Schubert, and A. Zebib, Numerical simulation of threedimensional thermal convection in a fluid with strongly temperaturedependent viscosity. J. Fluid Mech., 233, 299-328, 1991.

Patankar, S. V., Heat Transfer and Fluid Flow, Taylor and Francis, pp. 197, Philadelphia, Pa., 1980.

Peltier, W. R., Postglacial variations in the level of the sea-implications for climate dynamics and solid-earth geophysics, Rev. Geophys., 36, 603-689, 1998.

Peltier, W. R. and L. P. Solheim, Mantle phase transitions and layered chaotic convection, Geophys. Res. Lett., 10, 321-324, 1992.

Pollack, H. N., S. J. Hurter, and J. R. Johnson, Heat flow from the Earth's interior: Analysis of the global data set, Rev. Geophys., 31, 267-280, 1993.

Rhodes, M. and J. H. Davies, Tomographic imaging of multiple mantle plumes in the uppermost lower mantle, Geophys. J. Int., 147, 88-92, 2001.

Richter, F. M., Finite amplitude convection through a phase boundary, Geophys. J. R. Astron. Soc., 35, 265-276, 1973.

Richter, F. M. and B. Parsons, On the interaction of two scales of convection in the mantle, J. Geophys. Res., 80, 2529-2541, 1975.

Shen, Y., S. C. Solomon, I. T. Bjarnason, and C. J. Wolfe, Seismic evidence for a lower-mantle origin of the Iceland plume, Nature, 395, 62-65, 1998.

Sleep, N. H., Hotspots and mantle plumes: Some phenomenology, J. Geophys. Res., 95, 6715-6736, 1990.

Smolarkiewicz, P. K., A simple positive definite advection scheme with small implicit diffusion, Mon. Wea. Rev., 111, 479-486, 1983.

Smolarkiewicz, P. K., A fully multidimensional positive definite advection transport algorithm with small implicit diffusion, J. Comput. Phys., 54, 325-362, 1984.

Smolarkiewicz, P. K. and T. L. Clark, The multidimensional positive definite advection transport algorithm: Further development and applications, J. Comput. Phys., 67, 396-438, 1986.

Solheim, L. P. and W. R. Peltier, Avalanche effects in phase transition modulated thermal convection: A model of Earth's mantle, J. Geophys. Res., 99, 6997-7018, 1994a.

Solheim, L. P. and W. R. Peltier, Phase boundary deflections at $660-\mathrm{km}$ depth and episodically layered isochemical convection in the mantle, $J$. Geophys. Res., 99, 15861-15875, 1994b.

Solomatov, V. S., Scaling of temperature- and stress-dependent viscosity convection. Phys. Fluids, 7, 266-274, 1995.

Steinbach, V. and D. A. Yuen, Effects of depth-dependent properties on the thermal anomalies produced in flush instabilities from phase transitions, Phys. Earth Planet. Int., 86, 165-183, 1994.

Steinbach, V. and D. A. Yuen, The effects of temperature-dependent viscosity on mantle convection with the two major phase transitions, Phys. Earth Planet. Int., 90, 13-36, 1995.

Steinbach, V. and D. A. Yuen, Dynamical effects of a temperature- and pressure-dependent lower-mantle rheology on the interaction of upwellings with the transition zone, Phys. Earth Planet. Int., 103, 85-100, 1997.

Steinbach, V., D. A. Yuen, and W. Zhao, Instabilities from phase transitions and the timescales of mantle thermal evolution, Geophys. Res. Lett., 20, 1119-1122, 1993.

Su, W., R. L. Woodward, and A. M. Dziewonski, Degree 12 model of shear velocity heterogeneity in the mantle, J. Geophys. Res., 99, 6945-6980, 1994.

Tackley, P. J., Effects of strongly variable viscosity on three-dimensional compressible convection in planetary mantles, J. Geophys. Res., 101, 3311-3332, 1996a.

Tackley, P. J. On the ability of phase transitions and viscosity layering to induce long wavelength heterogeneity in the mantle, Geophys. Res. Lett., 23, 1985-1988, 1996b.

Tackley, P. J., Self-consistent generation of tectonic plates in timedependent, three-dimensional mantle convection simulations 2. Strain weakening and asthenosphere, Geochem. Geophys. Geosyst., 1, 2000GC000043, 2000.

Tackley, P. J., D. J. Stevenson, G. A. Glatzmaier, and G. Schubert, Effects of endothermic phase transition at $670 \mathrm{~km}$ depth in a spherical model of convection in the Earth's mantle, Nature, 361, 699-704, 1993.

Tackley, P. J., D. J. Stevenson, G. A. Glatzmaier, and G. Schubert, Effects of multiple phase transitions in a 3-dimensional spherical model of 
convection in Earth's mantle, J. Geophys. Res., 99, 15877-15901, 1994. Turcotte, D. L. and G. Schubert, Geodynamics, Second Edition, Cambridge Univ. Press, pp. 456, Cambridge, U.K., 2002.

Weinstein, S. A., Catastrophic overturn of the Earth's mantle driven by multiple phase changes and internal heat generation, Geophys. Res. Lett., 20, 101-104, 1993.

Wessel, P. and W. H. F. Smith, New, improved version of the Generic Mapping Tools released, EOS Trans. Am. Geophys. Union, 79, 579, 1998.

White, W., Sources of oceanic basalts: Radiogenic isotopic evidence, $\mathrm{Ge}$ ology, 13, 115-118, 1985.

White, R. and D. McKenzie, Magmatism at rift zones: The generation of volcanic continental margins and flood basalts, J. Geophys. Res., 94, 7685-7729, 1989.

Williams, Q., J. Revenaugh, and E. Garnero, A correlation between ultralow basal velocities in the mantle and hot spots, Science, 281, 546-549, 1998.

Yoshida, M., Numerical studies on the dynamics of the Earth's mantle convection with moving plates, Ph.D. Thesis, Univ. of Tokyo, pp. 203, 2003.
Yoshida, M., Possible effects of lateral viscosity variations induced by plate-tectonic mechanism on geoid inferred from numerical models of mantle convection, Phys. Earth Planet. Int., 147, 67-85, 2004.

Yoshida, M. and M. Ogawa, The role of hot uprising plumes in the initiation of plate-like regime of three-dimensional mantle convection, Geophys. Res. Lett., 31, L05607, doi:10.1029/2003GL017363, 2004.

Yuen, D. A., D. M. Reuteler, S. Balachandar, V. Steinbach, A. V. Malevsky, and J. J. Smedsmo, Various influences on three-dimensional mantle convection with phase transitions, Phys. Earth Planet. Int., 86, 185-203, 1994.

Zhao, D., Seismic structure and origin of hotspots and mantle plumes, Earth Planet. Sci. Lett., 192, 251-265, 2001.

Zhao, W., D. A. Yuen, and S. Honda, Multiple phase transitions and the style of mantle convection, Phys. Earth Planet. Int., 72, 185-210, 1992.

Zhong, S. and M. Gurnis, Role of plates and temperature-dependent viscosity in phase change dynamics, J. Geophys. Res., 99, 15903-15917, 1994.

M. Yoshida (e-mail: myoshida@jamstec.go.jp) 